\title{
WHICH GROUP SHOULD GOVERNMENTAL POLICIES TARGET? EFFECTS OF INCENTIVE POLICY FOR REMANUFACTURING INDUSTRY
}

\author{
Kai LiU ${ }^{1}$, ChuanXu WAng ${ }^{1}$, Lin LiU ${ }^{2,3, *}$ And LANG XU ${ }^{4}$
}

\begin{abstract}
Although previous research ignores other subsidy groups, we conduct a comprehensive study. In our closed-loop supply chain model, the manufacturer can produce either new products or remanufactured products of end-of-life products recycled by independent recyclers. Our core objective is to explore the production and recycling strategies of the two products under different government subsidy plans and which groups the government subsidy plans should target. Considering the consumers' discount perception and uncertainty of recycling quantity, we construct four game scenarios: (1) no subsidy (Scenario $N$ ); (2) subsidy for the manufacturer (Scenario $M$ ); (3) subsidy for the recycler (Scenario $R$ ); (4) subsidy for consumers (Scenario $C$ ). The results show that the corporate profits and social welfare under scenario $C$ are higher than those under other scenarios. If the government adopts scenario $C$, enterprise profits and social welfare will always be higher, but the downside is that government expenditure will also be higher. If considering the limited government funds, the government can set a medium subsidy level. Scenario $M$ will bring sub-optimal social welfare to the government. For scenario $R$, government subsidies stimulate the recycling of end-of-life products and help recyclers increase their profits, but from the manufacturer's perspective, manufacturers may resist this scenario.
\end{abstract}

Mathematics Subject Classification. 90B05.

Received June 24, 2020. Accepted January 22, 2021.

\section{INTRODUCTION}

In recent years, with the acceleration of the upgrading of electronic products, the amount of e-waste (e.g., TV, refrigerator, printer, etc.) has increased dramatically, and the ecological environment has continued to deteriorate [62]. As reported, it is estimated that in 2021, more than 50 million tons of e-waste will be generated, but only $15 \%$ will be recycled [10]. It's worth noticing the growth of second-hand electronic products also aggravates resource consumption and environmental pollution, in which the percentage of recycled material in discarded electronic products is relatively low. Still, the recycling potential of materials is great. If the resource such as gold, silver, platinum and other resources contained in them can be reasonably used, the economic and

Keywords. Remanufacturing strategy, government subsidy, consumer preference, Stackelberg game.

1 School of Economics \& Management, Shanghai Maritime University, Shanghai, P.R. China.

2 School of Economics and Management, Tongji University, Shanghai, P.R. China.

3 Navy Medical Center of PLA, The Second Military Medical University, Shanghai, P.R. China.

4 College of Transport and Communications, Shanghai Maritime University, Shanghai, P.R. China.

* Corresponding author: earnestliu@126.com 
social benefits will be obtained. In addition, the governments have also taken legal measures, and required manufacturers to recycle end-of-life (EOL) products and further utilize scrapped products.

According to Mcconocha and Speh [33], remanufacturing has created many benefits, such as saving labor, material and energy consumption, shortening the lead time of enterprises, expanding new markets and improving the social image of enterprises. In fact, much of Apple's supply chain is driven by renewable energy, announced in 2017 that all final products would be green and environmental friendly. Therefore, remanufacturing, as an effective method to decrease cost and improve efficiency, has become the focus of the industry and academia. Consumer perceptions of remanufactured products will affect their buying behavior and decision making [52]. However, in the market economic environment, consumer's attitude has changed greatly, and remanufacturing products are difficult to sell. From the consumer's perspective, the incentive to buy remanufactured products may be lower. From the perspective of collection enterprises, recycling is uncertain since arrival time, quality, and quantity of recycled products directly affect the enterprise's profit [21,58]. Hence, it's advisable to investigate the uncertainty of consumer preference and recycling in closed-loop supply chain (CLSC).

However, it is unrealistic for enterprises to develop remanufacturing industries by themselves, mainly because the required investment is at great expense. Government subsidy as a powerful tool to stimulate enterprises to promote the circular economy plays a vital role in CLSC. For instance, auto replacement plan, replacement of household electrical appliance program [63]. In November 2015, other policies were formulated for recycling WEEE, which subsidized recycler to encourage recyclers to recycle EOL electronic products. Although the above policies have achieved good results, such as promoting the development of remanufactured products and reducing environmental pollution, they have also brought enormous financial pressure on the government. Therefore, ensuring the effective implementation of government subsidy policies is inseparable from the joint participation of governments, enterprises, and consumers.

Different subsidy modes have different effects on the equilibrium decision and social welfare of each member in the CLSC. In the existing literature on government subsidies, most scholars only consider one kind of government subsidy mode, such as consumer subsidies (e.g., [31]). Some scholars compared the differences between government subsidies for manufacturers and consumers (e.g., $[53,64])$. Yet, we consider all participants in the CLSC, which is more comprehensive. We attempt to answer the following question: Which group should governmental subsidy policies target? Specifically, we address the following issues:

- For members, what is the optimal level of subsidy for different modes of government subsidies? And what impact will it have on the recycling quantity and production quantity of the two products?

- For consumers, enterprises, or society, which subsidy mode is most beneficial? And what factors will be critical to the results?

- Do remanufacturing cost savings and consumer preferences affect CLSC decision strategies? What measures should the government take to improve social welfare?

Aiming at these problems above, we use the scenario of no government subsidy as a benchmark model and then expand on three scenarios in which the government subsidizes manufacturers, recyclers, or consumers. In the benchmark model, both the manufacturer (Leader) and the recycler (Follower) aim to maximize their own profits. The game order is as follows: the manufacturer first determine the sales quantity of the two products, and then the recycler determine the quantity of recycling. In other government subsidy models, the government makes the first decision, and its goal is to maximize social welfare. The game order in these three models is as follows: the government moves first than the manufacturer and the recycler, that is, the government first determine the level of subsidy, then the manufacturer move, and finally the recyclers move after observing the manufacturer's decision.

The rest of this paper is described below: Section 2 combed the relevant literature from three perspectives. We describe and assume the model in Section 3. The optimal decision solutions are obtained for the benchmark model (excluding government subsidies) and the other models with three types of subsidy (subsidizing manufacturer, recycler, and consumer) in Section 4. Section 5 presents the equilibrium results and compares the difference of 
optimal results among the three models. In Section 6, we analyze and compare the effects of related parameters. In Section 7, a summary of this paper and prospects. The proofs are in the Appendix A.

\section{Literature REVIEW}

The literature in this article is divided into three categories: Section 2.1 focus on consumer preference in a supply chain. And then, we discuss CLSC decision in Section 2.2. In Section 2.3, we discuss the government subsidy in a CLSC. Section 2.4 introduces the research gaps and contributions of this paper.

\subsection{Consumer preference in a supply chain}

Different consumers have different types of preferences for products, which is an essential factor affecting product sale $[1,44]$. Therefore, some consumers are more environmentally conscious and prefer environmentally friendly products when choosing products, such as low-carbon product $[8,41,62]$ and remanufactured product $[7,62,64]$. Besides, consumer preference will also make a difference to enterprise profits and the supply chain operation efficiency [14]. Atasu et al. [2] studied the impact of different willingness to pay for consumers (ordinary consumers and green consumers) on purchasing behavior. In a two-period CLSC network, Xiong et al. [54] investigated the impact of consumer preference on equilibrium output of different products. Du et al. [9] found that consumer preference was positively correlated with channel profits. Some scholars also analyzed the influence of consumer preference from the perspective of dual-channel and multi-channel $[28,29]$. Furthermore, some scholars have made analyses from the empirical perspective. Shuai et al. [47] studied the low-carbon preferences of consumers in six Chinese cities and found that consumers' willingness to pay was significantly different. Motoshita et al. [36] investigated consumers' daily shopping choices and analyzed the changes in consumers' buying intentions to products. Thus, the effect of consumer preferences on enterprise profits and operations is evident. Similarly, we assume that consumers are environmentally conscious, but we focus on recycling and production decisions.

\subsection{The CLSC decision}

In recent years, the influence of product recycling and remanufacturing on CLSC decisions has attracted extensive attention from scholars. Many other studies have also examined CLSC under uncertain conditions, such as uncertain demand $[25,26]$, uncertain recycling quality $[24,37]$ or uncertain recycling quantity $[19,38]$. In terms of pricing and coordination, Banker [3] explored the influence of uncertain demand on production and pricing strategies. Ferrer and Swaminathan [12] analyzed the remanufacturing and pricing strategies of two products in different cycles. Based on the uncertainty of supply and demand, $\mathrm{Hu}$ and Feng [22] investigated the optimal price decision and coordination conditions under service demand. Also, several scholars have studied the uncertainty of relevant parameters in the design of the CLSC network $[18,40]$. Moreover, in terms of CLSC recycling channels, Savaskan et al. [45] analyzed the choice of recycling channels and pricing decisions of manufacturers and retailers. Feng et al. [13] studyed the supply chain coordination strategies of three recycling channels based on consumer preferences. Meanwhile, Li et al. [29] extended study to the impact of random demand for remanufactured products on the reverse supply chain. These pieces of literature have made essential contributions to the uncertainty analysis of CLSC and the comparison of recovery channels from different perspectives, these literature studies focus on demand uncertainty. Different from them, the influence of the uncertain recycling quantity on an enterprise's equilibrium decision in a realistic situation, this is our following work.

In fact, enterprises not only pay attention to profit issues when making decisions, but risks may also have a greater impact on the enterprise $[27,32,42,48]$. Therefore, it is necessary for enterprises to consider risk factors in a CLSC. Choi et al. [5] studied how a risk averse manufacturer and two risk averse competing retailers affect supply chain profitability and pricing decisions. Qu et al. [43] incorporates shipping policies and default risks into the green supply chain, and the manufacturer may deliver free shipping to the retailer, depending on the retailer's order quantity. Gupta and Ivanov [16] further studied how the competitive supplier's risk aversion and supply disruption affects firms' pricing decisions. However, the above literature focuses on the impact of 
enterprise risk aversion on operation decisions of CLSC, while ignoring consumer's risk aversion. Recently, Deng [8] analyzed the impact of consumer's risk aversion on enterprise pricing decisions and the environment. Different from the research of Deng [8], we explored the impact of consumer's risk aversion on operation decisions and profits under different subsidy models.

\subsection{Government subsidy in a CLSC}

Developing circular economy and to realize green transformation, the government playing a significant role in the CLSC characterized by EOL product recycling [17,57]. By providing subsidies, tax exemptions, loans, and other measures, the government can not only stimulate the enthusiasm of supply chain participants in recycling, but also effectively promote remanufacturing activities, bringing social, economic, and environmental benefits $[50,55,56]$. The government subsidy policies related to this article mainly involve subsidy for the manufacturer, subsidy for the recycler, and subsidy for consumers. In terms of subsidy for the manufacturer, Mitra and Webster [35] analyzed the practical significance of government subsidies to manufacturers and remanufacturers' profits, and the results showed that part of the subsidy should be given to the manufacturer. Nielsen et al. [39] studied the impact of subsidy for the manufacturer (to stimulating product recycling), subsidy for the manufacturer (to improving product quality) and subsidy for consumers on pricing and social welfare under different power structures. The results show that if the government's goal is to increase green consumption, the effect of subsidy for consumers is better, but if the government's goal is to effectively use subsidy expenditures, the government should choose to subsidy for the manufacturer (to improving product quality). The difference is that we are to reduce the cost of remanufacturing products. In terms of subsidy for the recycler, Wang et al. [49] analyzed the impact of recycling subsidy on the remanufacturing industry based on system dynamics, and the results showed that recycling subsidy should be set at medium or high level. Liu et al. [30] analyzed the impact of equilibrium recycling prices and subsidy strategy on formal and informal channels, where the government provides subsidies to formal recyclers.

Also, for consumer subsidy, based on government budget constraints, Huang et al. [23] explored the influence of consumer subsidies on energy-efficient product prices and product energy efficiency, and the results showed that the government's certification standard and subsidy level should take into account the capabilities of enterprises themselves, and unfavorable and exorbitant. Cohen et al. [6] studied the impact of consumer subsidies on supplier production and pricing strategies based on uncertain demand and minimization of government expenditures, and found that demand uncertainty is positively correlated with production quantity, but is opposite to price. However, the above research did not consider social welfare. From the social welfare point of view, Shao et al. [46] compared two different incentive plans and found that the government tends to use consumer subsidy plans, while environmental factors have a great impact on social welfare. Xu et al. [58] established a supply chain model in which the government taxed high-carbon manufacturers and provided subsidy to low-carbon consumers, and studied the impact of horizontal integration strategies on social welfare. Yu et al. [61] discussed the effect of different government subsidy plans and government goals on the equilibrium strategy of enterprises and social welfare. Their results showed that when the government aims to improve social welfare, subsidizing consumers is more robust. He et al. [20] analyzed the optimal government subsidy level and social welfare under three channel structures, and the results showed that high subsidy can benefit consumers and enterprises, but may not be conducive to the environment. Furthermore, He et al. [20] only considered consumer subsidy and did not consider risk factors. Recently, Bian et al. [4] discussed the impact of manufacturer subsidy and consumer subsidy on investment in emission reduction technologies, and which subsidy the government should implement depends on whether the government focuses on cost or social welfare. Our study differs from Bian et al. [4] in two aspects. First, unlike Bian et al. [4], we not only consider the manufacturer subsidy and consumer subsidy, but also consider the scenarios of without subsidy and recycler subsidy. Moreover, Bian et al. [4] consider the financial risk of the manufacturer, but they did not consider the consumers' risk aversion. 


\subsection{Research gaps and our contributions}

According to the differences between the existing literature and this paper (shown in Tab. 1), this article has contributed in the following areas: First, we have studies four different subsidy objects, which are more comprehensive. Second, previous papers considered the uncertainty of demand and quality in the supply chain, we further consider the uncertainty of recycling quantity in the three-tier supply chain Stackelberg game. Third, we conduct a comprehensive analysis of different subsidy scenarios from the perspectives of consumers, enterprises and government and give reasonable policy recommendations and managerial insights. Fourth, we further explore the impact of consumers' risk aversion on the equilibrium strategy under different subsidy scenarios.

\section{Model DESCRIPTION AND NOTATIONS}

We consider a CLSC consisting of the government, one manufacturer $(M)$, and one recycler $(R)$. The manufacturer can produce new products and remanufactured products, and sell them to consumers at prices $p_{n}$ and $p_{r}$, respectively. At the same time, the manufacturer entrusts the recycler to recycle the EOL products, the recycling price is $v$, and the manufacturer's unit transfer price is $w_{r}$. In real life, the government often adopts different means of fiscal policy to achieve specific political and economic goals [34]. The government subsidy is a powerful tool to promote the development of the remanufacturing industry. Different subsidies have a significant impact on the efficiency of CLSC operations. Therefore, we designed four different subsidy models (without government subsidy, subsidy for the manufacturer, subsidy for recycler and subsidy for consumers), the purpose of which is to determine which subsidy model is more effective.

We only consider consumers' purchase of a single product, i.e., a new product or remanufactured product. All EOL products recovered by recyclers from consumers can be processed into remanufactured products. $\Delta=$ $c_{n}-c_{r}>0$ represents the unit cost savings, where the unit cost of a new product produced by the manufacturer is $c_{n}$, the unit cost of a remanufactured product is $c_{r}$, and the unit recycling price for the recycler is $v$, both of which include transportation costs (e.g., [11,59]). To ensure the economy of the remanufacturing activity and ensure the non-negative profit of the recycler, the following conditions need to be met: $w_{r}>c_{1}>v>k$.

In the research, the remanufactured product has no difference from the new product in quality and function. Due to consumers' inconsistent sense of identity to the two products, it will affect consumers' purchasing behaviour and decision. We assume that the market size is 1, the utility of consumers buying a new product is $e$, and follow uniform distribution between 0 and 1 . Relative to the recycling price of the new product, the lowest acceptance of the recycling price of the remanufactured product is $\theta$ and $\theta \in[0,1]$. Therefore, in the without government subsidy scenario, the utility functions of the two products are $U_{n}^{N}=e-p_{n}, U_{r}^{N}=\theta e-p_{r}$, respectively. So, the linear inverse demand functions are $P_{r}^{N}=\theta\left(1-Q_{n}-Q_{r}\right)$ and $P_{n}^{N}=1-Q_{n}-\theta Q_{r}$, respectively.

The government and enterprises take the absolute initiative in the game relationship between product recycling and remanufacturing. By formulating subsidy policies, the government provides subsidies to manufacturers, recyclers, and consumers are $m, k$, and $s$. Maximizing social welfare is widely applied in remanufacturing literature, and according to the government objective function proposed by Fu et al. [14] and Xu et al. [60], which contains the following four key elements: (1) The manufacturers' profit $\pi_{m}^{i}$; (2) The recycler' profit $\pi_{r}^{i}$; (3) The total consumer surplus $\mathrm{CS}^{i}$; (4) The total government subsidy expenditure $\mathrm{GS}^{i}$. Therefore, it can be expressed as:

$$
\mathrm{SW}^{i}=\pi_{m}^{i}+\pi_{r}^{i}+\mathrm{CS}^{i}-\mathrm{GS}^{i}=\pi_{m}^{i}+\pi_{r}^{i}+\left(\int_{1-Q_{n}^{j *}}^{1}\left(e-p_{n}^{j *}\right) \mathrm{d} e+\int_{1-Q_{n}^{j *}-Q_{r}^{j *}}^{1-Q_{n}^{j *}}\left(\theta e-p_{r}^{j *}\right) \mathrm{d} e\right)-i Q_{r}^{i *} .
$$

Besides, the recovery of the EOL product is distributed uniformly between 0 and 1 . The probability density function is $f(\lambda)$ and the cumulative distribution function is $F(\lambda) . \pi_{l}^{i}$ is used to represent the profit of enterprises $l$ in model $i(i=\{N, M, R, C\}) \cdot m^{*}, k^{*}$, and $s^{*}$ represents the optimal level of government unit subsidies to 


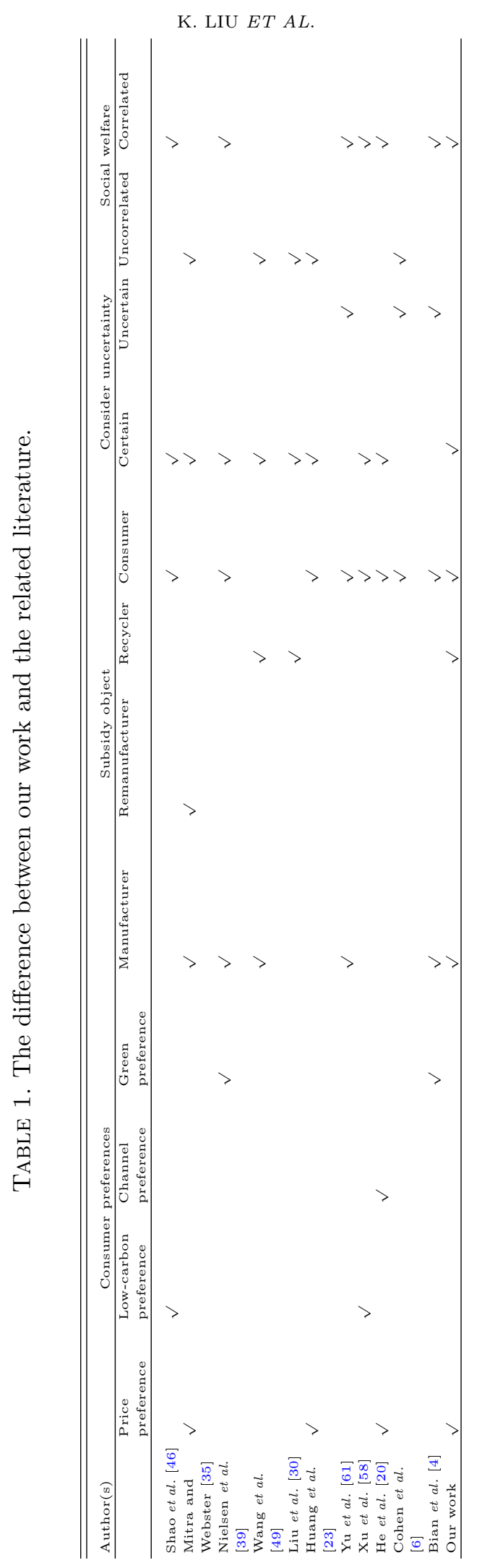


TABLE 2. Notation and explanation.

\begin{tabular}{ll}
\hline \hline Notation & Explanation \\
\hline$p_{j}$ & The sales price of the new / remanufactured products, $j=n, r$ \\
$Q_{j}$ & The quantity of products \\
$c_{j}$ & The unit cost of products \\
$\Delta$ & Unit cost savings for remanufactured products \\
$c_{1}$ & Emergency procurement cost \\
$w_{r}$ & Unit transfer price of EOL products \\
$\theta$ & Consumers' perception of discount on remanufactured products, $0<\theta<1$ \\
$R$ & Recycling quantity of EOL products \\
$\lambda$ & Recovery rate \\
$e$ & The willingness of consumers to buy new products \\
$v$ & Recycling price \\
\hline
\end{tabular}

the manufacturer, recycler, and consumers, respectively. Among of them, the anarchic subsidy model is the benchmark model, which is used to compare the effects of different government subsidy plans on equilibrium strategies and economic benefits. All notations are shown in Table 2.

\section{SUBSIDY MECHANISM DESIGN}

We first discuss the case of no subsidy as a benchmark model and then investigate the subsidy for the manufacturer, subsidy for the recycler, subsidy for consumers, and we sequentially analyze the equilibrium results.

\subsection{Benchmark model: decisions without government subsidy (Scenario $N$ )}

In the benchmark model (without government subsidy), the manufacturer (Leader) first determines the sales quantity of new and remanufactured products. After observing the manufacturer's remanufactured product sales, the recycler (Follower) decides the quantity of recycled products. If the recycler finds that the quantity recycled is less than the observed quantity of remanufactured products, it will adopt an urgent ordering strategy. Otherwise, it will result in a loss of profits. Hence, the manufacturer's and recycler's profit functions are abtanied as:

$$
\begin{aligned}
& \pi_{m}^{N}=\left(p_{n}-c_{n}\right) Q_{n}+\left(p_{r}-c_{r}\right) Q_{r}-w_{r} Q_{r} \\
& \pi_{r}^{N}=w_{r} Q_{r}-c_{1}\left[Q_{r}-\lambda R\right]^{+}-v R .
\end{aligned}
$$

In (4.1), the first term represents the profit from selling the new products. The second term represents the profit from selling remanufactured products. The last term represents the transfer payment cost that the manufacturer pays to the recycler. In (4.2), the first term is the recycler's revenue. The second term represents the emergency procurement costs. The last term represents the cost of recycling EOL products.

To solve the above problems, we can get the optimal sales quantity of the manufacturer's two products, the optimal recycled quantity of the recycler, and their own profits. The superscript ${ }^{*}$ and $i$ to represent the optimal solution for the four subsidy scenarios.

Proposition 4.1. In scenario $N$, the optimal recycling quantity is $R^{N^{*}}=\frac{w_{r}-\theta c_{n}+c_{r}}{2 \theta(-1+\theta)} \sqrt{\frac{c_{1}}{2 v}}$. The sales quantity and sales price of the two products are

$$
Q_{r}^{N *}=\frac{w_{r}-\theta c_{n}+c_{r}}{2(-1+\theta) \theta}, Q_{n}^{N^{*}}=\frac{1+w_{r}-\theta-c_{n}+c_{r}}{2-2 \theta}, p_{r}^{N^{*}}=\frac{w_{r}+\theta+c_{r}}{2}, p_{n}^{N^{*}}=\frac{1+c_{n}}{2} .
$$


By Proposition 4.1, the optimal recycling quantity $R^{N *}$ is positively correlated with the sales quantity of the remanufactured product $Q_{r}^{N *}$, both $Q_{r}^{N *}$ and $Q_{n}^{N *}$ are determined by the parameters $w_{r}, \theta, c_{n}$ and $c_{r} . p_{r}^{N *}$ is positively correlated with $w_{r}, \theta$ and $c_{r}$, while $p_{n}^{N *}$ is only positively correlated with $c_{n}$.

\subsection{Subsidy for the manufacturer (Scenario $M$ )}

As the core role of the CLSC, remanufacturing is one of the important development directions of manufacturers. The government has formulated relevant policies to provide financial subsidies to energy-conserving production enterprises. For example, On May 26, 2010, the Chinese government issued the "Energy Saving Products Benefit People Project" implementation rules [23]. Chinese automakers have received government subsidies to promote energy-efficient vehicles, with a subsidy standard of 3000 yuan per vehicle. This section assumes that the government encourages the manufacturer to continuously invest in remanufacturing activities by subsidizing $m$ per unit of the remanufactured product produced by the manufacturer. Financial subsidy indirectly reduces the manufacturer's remanufacturing costs, thus increasing its profits. The manufacturer's and recycler's profit functions are:

$$
\begin{aligned}
& \pi_{m}^{M}=\left(p_{n}-c_{n}\right) Q_{n}+\left(p_{r}-c_{r}+m\right) Q_{r}-w_{r} Q_{r} \\
& \pi_{r}^{M}=w_{r} Q_{r}-c_{1}\left[Q_{r}-\lambda R\right]^{+}-v R .
\end{aligned}
$$

Proposition 4.2. In scenario $M$, the optimal recycling quantity of the recycler is $R^{M}=\frac{m-w_{r}+\theta c_{n}-c_{r}}{2 \theta(1-\theta)} \sqrt{\frac{c_{1}}{2 v}}$. The sales quantity and sales price of the new and remanufactured products are, $Q_{n}^{M^{*}}=\frac{1-m+w_{r}-\theta-c_{n}+c_{r}}{2(1-\theta)}, Q_{r}^{M^{*}}=$ $\frac{m-w_{r}+\theta c_{n}-c_{r}}{2 \theta-2 \theta^{2}}, p_{n}^{M^{*}}=\frac{1+c_{n}}{2}, p_{r}^{M *}=\frac{w_{r}+\theta-m+c_{r}}{2}$. The optimal subsidy value is $m^{*}=w_{r}-\sqrt{2 v c_{1}}+\theta c_{n}-c_{r}$.

By Proposition 4.2, the optimal recycling quantity $R^{M *}$ is positively correlated with the sales quantity of the remanufactured product $Q_{r}^{M^{*}}$. Also, the recycling quantity and the remanufactured product sales quantity have been improved due to the influence of unit subsidy $(m)$, while the new product sales quantity is opposite. $p_{r}^{M^{*}}$ is negatively correlated with $m$, while $p_{n}^{M^{*}}$ is only positively correlated with $c_{n}$. The optimal unit subsidy levels of subsidy for manufacturers are related to parameters $w_{r}, \theta, c_{n}, c_{r}, c_{1}$ and $v$.

\subsection{Subsidy for the recycler (Scenario $R$ )}

Recycler, as a recycling enterprise of EOL product, guarantee the smooth operation of the whole product CLSC. To recycle EOL products, government agencies stimulate recyclers to put more efforts into recycling EOL products by providing unit subsidy $k$ to the recycler. For example, according to the Waste Electrical and Electronic Products Recycling Management Regulations issued by the Chinese government, recycling enterprises can get subsidies for disassembling waste products (e.g., 85 yuan per TV set and 80 yuan per refrigerator). Hence, the manufacturer's and recycler's profit functions are:

$$
\begin{aligned}
& \pi_{m}^{R}=\left(p_{n}-c_{n}\right) Q_{n}+\left(p_{r}-c_{r}\right) Q_{r}-w_{r} Q_{r} \\
& \pi_{r}^{R}=w_{r} Q_{r}-c_{1}\left[Q_{r}-\lambda R\right]^{+}-(v-k) R .
\end{aligned}
$$

Proposition 4.3. In scenario $R$, the optimal recycling quantity of the recycler is $R^{R^{*}}=\frac{\theta c_{n}-c_{r}-w_{r}}{2 \theta(1-\theta)} \sqrt{\frac{c_{1}}{2 v-2 k}}$. The sales quantity and sales price of the two products are $Q_{r}^{R^{*}}=\frac{\theta c_{n}-c_{r}-w_{r}}{2 \theta(1-\theta)}, Q_{n}^{R^{*}}=\frac{1+w_{r}-\theta-c_{n}+c_{r}}{2-2 \theta}, p_{r}^{R^{*}}=$ $\frac{w_{r}+\theta+c_{r}}{2}, p_{n}^{R^{*}}=\frac{1+c_{n}}{2}$. The optimal subsidy value is $k^{*}=v$.

According to Proposition 4.3, the result is similar to Proposition 4.1. The optimal unit subsidy levels of subsidy for the rycler is related to parameter $v$. The optimal recycling quantity $R^{R^{*}}$ is positively correlated with the sales quantity of the remanufactured product $Q_{r}^{R^{*}}$. The optimal sales quantity and price of two products are not related to the subsidy. 
TABLE 3. Value range and size relation.

\begin{tabular}{ll}
\hline \hline Value range & Size relationship \\
\hline$w_{r}>v+2 \sqrt{2 v c_{1}}-\theta c_{n}+c_{r}$ & $k<m<s$ \\
$\frac{v(4 \theta-3)+2 \sqrt{2 v c_{1}}}{2 \theta-1}+\frac{(2 \theta-3)\left(\theta c_{n}-c_{r}\right)}{2 \theta-1}<w_{r}<v+2 \sqrt{2 v c_{1}}-\theta c_{n}+c_{r}$ & $m<k<s$ \\
$w_{r}<\frac{v(4 \theta-3)+2 \sqrt{2 v c_{1}}}{2 \theta-1}+\frac{(2 \theta-3)\left(\theta c_{n}-c_{r}\right)}{2 \theta-1}$ & $m<s<k$ \\
\hline
\end{tabular}

\subsection{Subsidy foronsumers (Scenario $C$ )}

Government agencies often promote the upgrading of the remanufacturing industry through directubsidies to consumers. When consumers buy remanufactured products that meet the requirements of national policies, the government directly gives a certain percentage of the sales price as a financial subsidy.

Suppose the government subsidizes per unit $s$ for consumers who purchase a remanufactured product [31]. The utility function becomes $U_{r}^{C}=\theta e-p_{r}+s$ and $U_{n}^{C}=e-p_{n}$, respectively. Linear inverse demand function becomes $p_{r}=\theta\left(1-Q_{n}-Q_{r}\right)+s, p_{n}=1-Q_{n}-\theta Q_{r}$, respectively. The manufacturer's and recycler's profit functions are:

$$
\begin{aligned}
& \pi_{m}^{C}=\left(p_{n}-c_{n}\right) Q_{n}+\left(p_{r}-c_{r}\right) Q_{r}-w_{r} Q_{r} \\
& \pi_{r}^{C}=w_{r} Q_{r}-c_{1}\left[Q_{r}-\lambda R\right]^{+}-v R .
\end{aligned}
$$

Proposition 4.4. In scenario $C$, the optimal recycling quantity of the recycler is $R^{C^{*}}=\frac{s-w_{r}+\theta c_{n}-c_{r}}{2 \theta-2 \theta^{2}} \sqrt{\frac{c_{1}}{2 v}}$. The sales quantity and sales price of the two products are $Q_{r}^{C^{*}}=\frac{s-w_{r}+\theta c_{n}-c_{r}}{2(1-\theta) \theta}, Q_{n}^{C^{*}}=\frac{1-s+w_{r}-\theta-c_{n}+c_{r}}{2(1-\theta)}, p_{r}^{C^{*}}=$ $\frac{w_{r}+\theta+s(2 \theta-1)+c_{r}}{2}, p_{n}^{C^{*}}=\frac{1+c_{n}}{2}$. The optimal subsidy value is $s^{*}=\frac{-2 \sqrt{2 v c_{1}}+w_{r}(2 \theta-1)+(3-2 \theta) \theta c_{n}+(2 \theta-3) c_{r}}{-3+4 \theta}$.

By Proposition 4.4, the result is similar to Proposition 4.2. $R^{C^{*}}$ and $Q_{r}^{C^{*}}$ are positively correlated with unit subsidy $s . p_{r}^{C^{*}}$ is positively affected by unit subsidy $s$ and increases the selling price, while $p_{n}^{C^{*}}$ is only positively correlated with $c_{n}$. The optimal unit subsidy levels of subsidy for consumers are related to parameters $w_{r}, \theta$, $c_{n}, c_{r}, c_{1}$ and $v$.

\section{DeCISIONS ANALYSIS IN THE FOUR DIFFERENT SUBSIDY MODELS}

We compare the level of government subsidies and the equilibrium results of the manufacturer and recycler under different subsidy models.

Theorem 5.1. The optimal government subsidy levels under different subsidy modes are ordered as the following.

Theorem 5.1 shows that under different government subsidy models, the amount of unit subsidy is different. Here, it can be divided into three cases. When $w_{r}$ is greater than a value, the unit subsidy amount of $S$ mode is the highest, and the unit subsidy amount of $K$ mode is the lowest; When $w_{r}$ is in a certain range, the unit subsidy amount of $\mathrm{s}$ mode is the highest, while m mode is the lowest; When $w_{r}$ is less than a value, the unit subsidy amount of $k$ mode is the highest, while that of $m$ mode is the lowest. Therefore, we need to study who is most effective for government subsidies.

Theorem 5.2. The optimal sales prices of new product are ordered as the following.

$$
p_{n}(N)=p_{n}(R)=p_{n}(M)=p_{n}(C) .
$$


Theorem 5.2 shows that under different government subsidy models, the sales price of new products is only related to the unit production cost of new products, and the unit government subsidies have no effect on the sales price of new products.

Theorem 5.3. The relationship between the sales price of remanufactured products is as follows.

$$
p_{r}(M)<p_{r}(N)=p_{r}(R)<p_{r}(C) .
$$

By Theorem 5.3, for the sales price of remanufactured products, the price of subsidy for consumers is the highest, while the price subsidy for the manufacturer is lower. The main reason is that the subsidy for consumers will inevitably increase the demand for remanufactured products, which will cause the price of remanufactured products to rise. Subsidy to manufacturers directly leads to the reduction of remanufacturing costs, which indirectly leads to the reduction of the product sales price.

Theorem 5.4. When $\max \left\{v, T_{1}\right\}<c_{1}\left\langle\min \left\{T_{2}, w_{r}\right\}, Q_{n}(M)\right\rangle Q_{n}(C)$. The production quantities of new product face the following relationships $Q_{n}(C)<Q_{n}(M)<Q_{n}(R)=Q_{n}(N)$. Where

$$
\begin{aligned}
& T_{1}=\frac{\left[(-1+\theta)\left(3-2 w_{r}+4\left(-1+w_{r}\right) \theta\right)+\left(3+\theta\left(-7+6 \theta-4 \theta^{2}\right)\right) c_{n}+2 \theta(-1+2 \theta) c_{r}\right]^{2}}{8 v(1-2 \theta)^{2}}, \\
& T_{2}=\frac{\left[w_{r}(2 \theta-1)+(3-2 \theta)\left(\theta c_{n}-c_{r}\right)\right]^{2}}{8 v} .
\end{aligned}
$$

Theorem 5.4 shows that the quantity of new products produced in both subsidy for the manufacturer and subsidy for consumers are reduced compared to the no subsidy scenario, among which, the result of the subsidy recycler is consistent with no government subsidy. By comparing the quantity of new products produced by scenarios $M$ and $C$, we find that when $\max \left\{v, T_{1}\right\}<c_{1}\left\langle\min \left\{T_{2}, w_{r}\right\}, Q_{n}(M)\right\rangle Q_{n}(C)$, the quantity of new products produced by scenario $M$ is greater than that produced by scenario $C$.

Theorem 5.5. When $v<c_{1}<\min \left\{\frac{\left(w_{r}+3 \theta c_{n}-3 c_{r}\right)^{2}}{32 v}, w_{r}\right\}$, the relationship is: $Q_{r}(N)=Q_{r}(R)<Q_{r}(M)<$ $Q_{r}(C)$.

Theorem 5.6. When $v<c_{1}<\min \left\{\frac{\left(w_{r}+3 \theta c_{n}-3 c_{r}\right)^{2}}{32 v}, w_{r}\right\}, R(M)>R(C)$, and when the government subsidy $k$ is trending to $v$, the relationship is: $R(N)<R(C)<R(M)<R(R)$.

By Theorem 5.5, the quantity of remanufactured products produced in both subsidy for the manufacturer and subsidy for consumers are increased compared to the no subsidy scenario, among which, the result of the subsidy recycler is consistent with no government subsidy. By comparing the optimal quantity of new products produced by scenarios $M$ and $C$, we find that when $v<c_{1}<\min \left\{\left(w_{r}+3 \theta c_{n}-3 c_{r}\right)^{2} / 32 v, w_{r}\right\}$, the quantity of remanufactured products scenario $C$ is higher than other scenarios. It is mainly because consumers are the end of the market and the beginning of the reverse supply chain. By Theorem 5.6, under certain conditions, scenario $R$ has the best recycling effect on EOL products, indicating that government subsidies for recyclers can effectively promote the recycling of EOL products.

\section{NUMENICAL ANALYSIS}

From the perspective of consumers, enterprises, and government, we use numerical experiments to illustrate the impacts of consumer discount perception and cost savings on the optimal decision of CLSC, different government subsidy levels, and the profits of manufacturers and recyclers. From this, we can compare the pricing, demand, profit and social welfare of new and remanufactured products under different models. Following assumptions for relevant literature [20], the values of the parameter in these papers can be adopted as follows: $c_{n}=0.06, c_{r}=0.01, c_{1}=0.035, \theta=0.9, w_{r}=0.042, v=0.014$. 
TABLE 4. The comparison of sales prices of remanufactured products under different modes $(\theta=0.9)$.

\begin{tabular}{lllllll}
\hline \hline \multicolumn{3}{c}{ Parameters } & \multicolumn{4}{c}{ Sales prices } \\
\hline$v$ & $\Delta$ & $c_{1}$ & $p_{r}(N)$ & $p_{r}(M)$ & $p_{r}(R)$ & $p_{r}(C)$ \\
\hline \multirow{2}{*}{0.014} & 0.05 & 0.015 & 0.476 & 0.453 & 0.476 & 0.506 \\
& & 0.03 & 0.476 & 0.462 & 0.476 & 0.495 \\
& & 0.035 & 0.476 & 0.464 & 0.476 & 0.492 \\
\cline { 2 - 7 } & 0.055 & 0.015 & 0.474 & 0.449 & 0.474 & 0.508 \\
& & 0.03 & 0.474 & 0.457 & 0.474 & 0.496 \\
& & 0.035 & 0.474 & 0.459 & 0.474 & 0.493 \\
\hline 0.02 & 0.05 & 0.03 & 0.476 & 0.468 & 0.476 & 0.487 \\
& & 0.035 & 0.476 & 0.470 & 0.476 & 0.484 \\
\cline { 2 - 7 } & 0.055 & 0.03 & 0.474 & 0.463 & 0.474 & 0.489 \\
& & 0.035 & 0.474 & 0.465 & 0.474 & 0.485 \\
\hline
\end{tabular}

\subsection{Consumer's perspective}

\subsubsection{The influence of different parameters on the sales price of remanufactured products}

We compared the sales prices of remanufactured products among different models and designed a variety of scenarios. It can be seen from Table 4 that recycling prices, cost savings and emergency procurement costs have an important role in the sales price of remanufactured products, where $p_{r}(C)$ has the highest sales price and $p_{r}(M)$ has the lowest sales price. This shows that scenario $C$ has the most significant influence on the sales price of remanufactured products. Besides, when the values of $\Delta$ and $c_{1}$ remain unchanged, as the recycling price increases, the value of $p_{r}(M)$ increases, while the value of $p_{r}(C)$ decreases. But it has no effect on the values of $p_{r}(N)$ and $p_{r}(R)$; When the values of $\Delta$ and $v$ remain unchanged, the impact of emergency procurement costs on the sales price of remanufactured products is consistent with the above; When the values of $v$ and $c_{1}$ are fixed, as the cost saving increases, the value of $p_{r}(C)$ shows an upward trend and the value of $p_{r}(N), p_{r}(M)$ and $p_{r}(R)$ shows a downward trend.

\subsubsection{The effect of different parameters on sales quantity of two products}

The sales quantity of new/remanufactured products of the four subsidy modes under different parameters is shown in Table 5. It can be shown that $Q_{n}(C)<Q_{n}(M)<Q_{n}(R)=Q_{n}(N), Q_{r}(N)=Q_{r}(R)<Q_{r}(M)<$ $Q_{r}(C)$. This indicates that government subsidies to manufacturers or consumers have a significant influence on the sales of products, and the lowest sales quantity of new products is $Q_{n}(C)$. In contrast, for remanufactured products, the sales quantity of $Q_{r}(C)$ is the highest. This verifies the Theorems 5.4 and 5.5. In addition, when the values of $\Delta$ and $c_{1}$ remain unchanged, as the recycling price increases, the value of $Q_{n}(M)$ and $Q_{n}(C)$ increases, but it has no effect on the values of $Q_{n}(N)$ and $Q_{n}(R)$. Similarly, for remanufactured products, the values of $Q_{n}(M)$ and $Q_{n}(C)$ tend to decrease. When the values of $\Delta$ and $v$ remain unchanged, as the emergency procurement cost increases, the value of $Q_{n}(M)$ and $Q_{n}(C)$ increases, while the value of $Q_{r}(M)$ and $Q_{r}(C)$ decreases. When the values of $v$ and $c_{1}$ are fixed, as the cost saving increases, the sales quantity of new products shows a downward trend, while the sales quantity of remanufactured products shows an upward trend.

\subsubsection{The impact of different parameters on quantity of two products}

Figure 1a shows, the number of new products of scenarios $M, N$, and $R$ is negatively correlated with consumers' perception and tends to 0 with the increase of consumers' perception. However, only when consumers' discount perception is within a certain range, the quantity of new products of scenario $C$ is meaningful, which first increases and then decreases. We can see that the quantity of new products in scenarios $M, R$, and $C$ is less than or equal to scenario $N$. In contrast, Figure 1c indicates that the quantity of remanufactured products 
TABLE 5. The comparison of sales quantity of new/remanufactured products under different modes $(\theta=0.9)$.

\begin{tabular}{cllllllllll}
\hline \hline \multicolumn{3}{c}{ Parameters } & \multicolumn{3}{c}{ Sales quantity $($ New product) } & \multicolumn{3}{c}{ Sales quantity (Remanufactured product) } \\
\hline$v$ & $\Delta$ & $c_{1}$ & $Q_{n}(N)$ & $Q_{n}(M)$ & $Q_{n}(R)$ & $Q_{n}(C)$ & $Q_{r}(N)$ & $Q_{r}(M)$ & $Q_{r}(R)$ & $Q_{r}(C)$ \\
\hline \multirow{2}{*}{0.014} & \multirow{2}{*}{0.05} & 0.015 & 0.46 & 0.235 & 0.46 & 0.082 & 0.011 & 0.261 & 0.011 & 0.432 \\
& & 0.03 & 0.46 & 0.32 & 0.46 & 0.22 & 0.011 & 0.167 & 0.011 & 0.274 \\
& & 0.035 & 0.46 & 0.343 & 0.46 & 0.262 & 0.011 & 0.141 & 0.011 & 0.231 \\
\cline { 3 - 10 } & 0.055 & 0.015 & 0.435 & 0.185 & 0.435 & 0.007 & 0.039 & 0.317 & 0.039 & 0.515 \\
& & 0.03 & 0.435 & 0.27 & 0.435 & 0.148 & 0.039 & 0.222 & 0.039 & 0.358 \\
& & 0.035 & 0.435 & 0.293 & 0.435 & 0.187 & 0.039 & 0.197 & 0.039 & 0.315 \\
\hline 0.02 & 0.05 & 0.03 & 0.46 & 0.376 & 0.46 & 0.317 & 0.011 & 0.104 & 0.011 & 0.169 \\
& & 0.035 & 0.46 & 0.404 & 0.46 & 0.364 & 0.011 & 0.073 & 0.011 & 0.118 \\
& 0.055 & 0.03 & 0.435 & 0.326 & 0.435 & 0.242 & 0.039 & 0.16 & 0.039 & 0.253 \\
& & 0.035 & 0.435 & 0.354 & 0.435 & 0.289 & 0.039 & 0.129 & 0.039 & 0.202 \\
\hline
\end{tabular}

is greater than or equal to the quantity of non-government subsidies. This further indicates that government subsidies are conducive to promoting the recycling of remanufactured products, improving the market demand for remanufactured products, stimulating consumers' consumption of remanufactured products, and thereby improving the environmental benefits of social production.

Figures $1 \mathrm{~b}$ and $1 \mathrm{~d}$ show that with the increase of cost saving, the quantity of new products will gradually decrease and the quantity of remanufactured products will gradually increase within a certain range regardless of the operation mode. Interestingly, when consumers were subsidized, the quantity of new products drops the most and the quantity of remanufactured products increases the most. In other words, the government subsidy plan promotes the upgrading of the remanufacturing industry and raises the level of remanufacturing cost saving.

\subsection{Enterprise's perspective}

\subsubsection{The impact of different parameters on manufacturer's profit}

According to Figure 2a, the manufacturer's profits of scenarios $N, R$ and $M$ is positively correlated with consumers' discount perception. However, in scenario $C$, when Consumers' discount perception was relatively small, the manufacturer's profit decreased with the increase of consumers' discount perception. Instead, when consumers' discount perception was relatively large, the manufacturer's profit gradually increased, presenting a process of first decreasing and then increasing. This may be because relatively hours in remanufacturing consumer preferences, consumer subsidies policy of the government, won the consumers a great deal of attention, but as the consumer, to the promotion of remanufacturing product awareness attention drops, also reflected in demand as you can see new products increased first and then manufactured goods to reduce, so cause manufacturers profit present from high to low down the process. When consumers have a relatively large preference for remanufactured products, they generally accept remanufactured products. We know the number of new products is gradually decreased and tends to zero, while the number of remanufactured products gradually increases, so does the manufacturers' profits rise accordingly. Meanwhile, when the government subsidizes consumers, manufacturers' profits increase the most. This is because consumers' acceptance of the remanufactured product gradually increases when consumers' discount perception increases and the remanufactured product has a stronger competitive advantage in market competition. And because consumers are closer to the market, manufacturers make the most money when the government subsidizes them.

Figure $2 \mathrm{~b}$ shows that there is a necessary connection between remanufacturing cost savings and manufacturer's profit. Among of them, the manufacturer's profit value and growth rate of scenario $C$ are the largest, followed by scenario $M$, while cost saving has no significant impact on scenarios $R$ and $N$. In conclusion, if manufacturers 


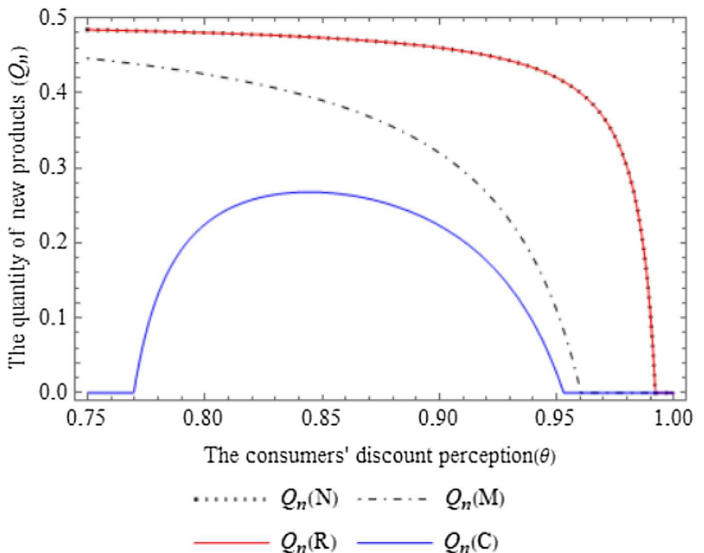

(a)

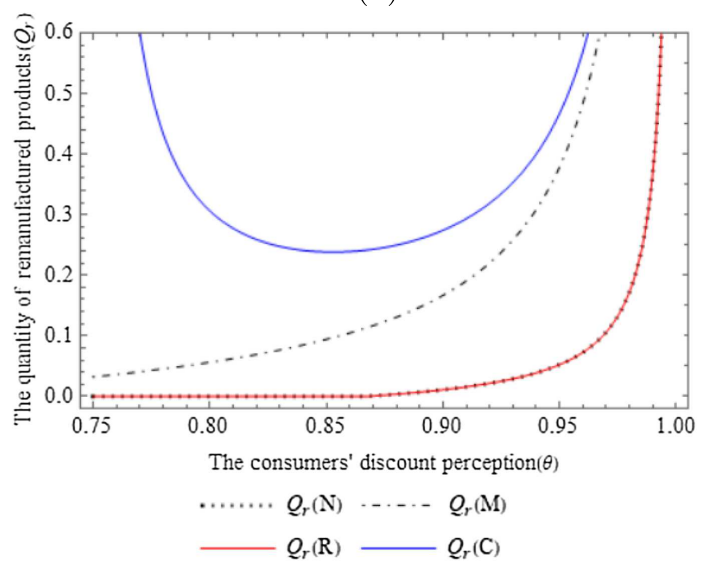

(c)

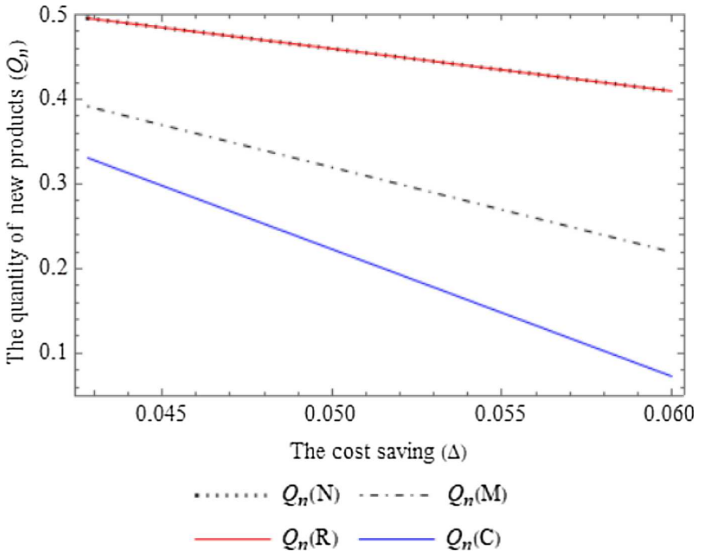

(b)

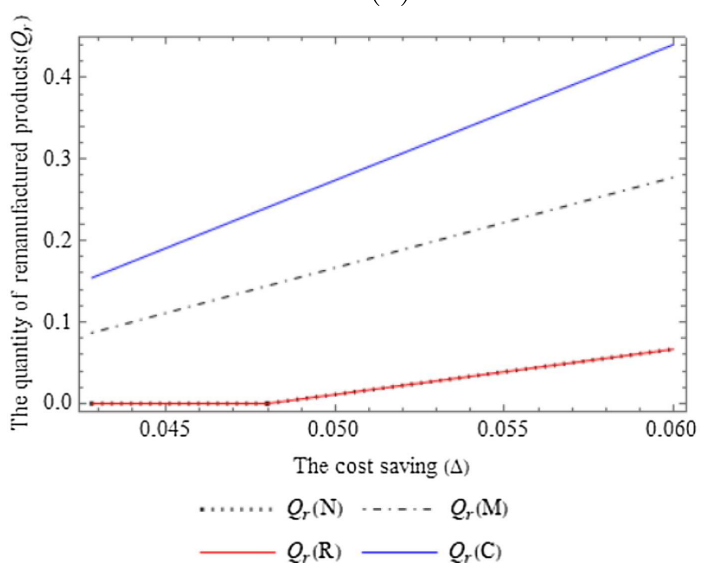

(d)

Figure 1. The impact of different parameters on quantity of two products. (a) The impact of $\theta$ on quantity of new product. (b) The impact of $\Delta$ on quantity of new product. (c) The impact of $\theta$ on quantity of remanufactured product. (d) The impact of $\Delta$ on quantity of remanufactured product.

want to gain more profits, they should constantly improve the remanufacturing technology level and result in significant cost savings.

\subsubsection{The impact of different parameters on recycler's profit}

It can be seen from Figure 3a that Consumers' discount perception has a similar effect on profits of recyclers as shown in Figure 2a. Moreover, when consumers' discount perception is larger than a certain value, profits of recyclers will be larger than that of non-government subsidies. From Figure 3b, with the increase of cost saving, the profits of recyclers will increase regardless of the subsidy model. Moreover, when cost saving is larger than a certain value, the profits of recyclers will be larger than that in the case of no subsidy. This shows that the profits of recyclers benefit from government subsidies. The above analysis shows that to gain more profits, recyclers should strengthen advocation to improve consumers' awareness of the remanufactured product. 


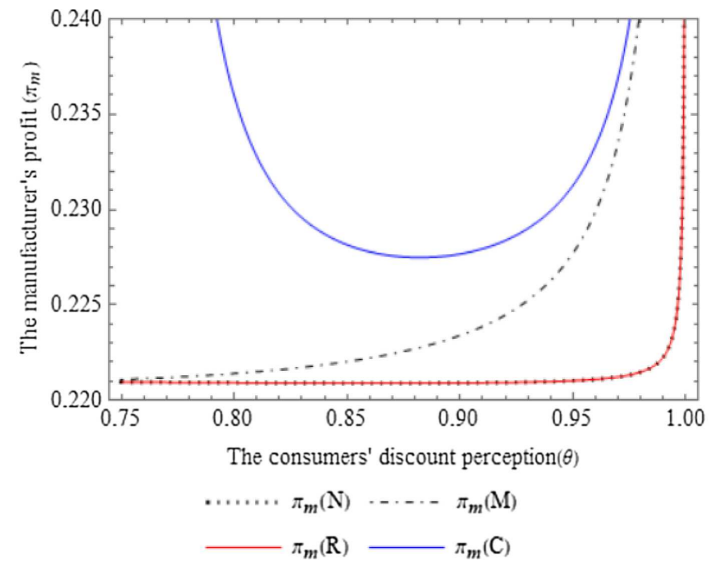

(a)

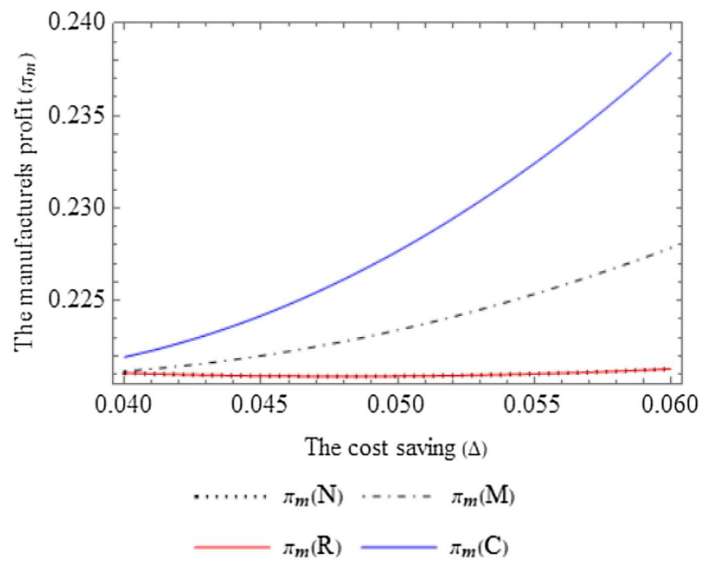

(b)

FiguRE 2. The impact of different parameters on manufacturer's profit. (a) The impact of $\theta$ on manufacturer's profit. (b) The impact of $\Delta$ on manufacturer's profit.

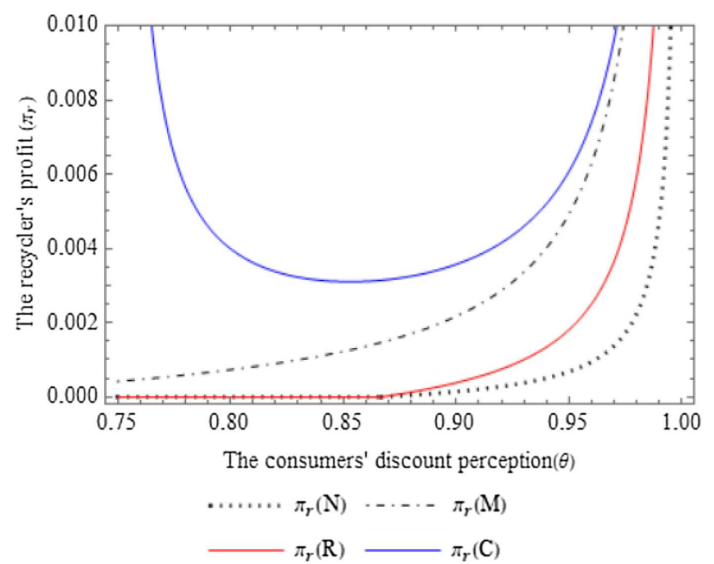

(a)

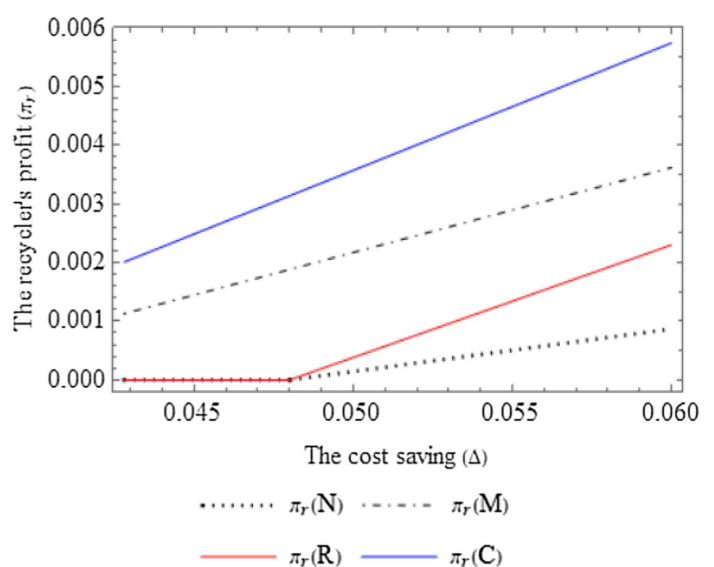

(b)

Figure 3. The impact of different parameters on recycler's profit. (a) The impact of $\theta$ on recycler's profit. (b) The impact of $\Delta$ on recycler's profit.

\subsection{Government's perspective}

\subsubsection{The comparison of optimal government subsidy levels under different scenarios}

In this section, we compared the sales prices of remanufactured products among different subsidy scenarios and designed a variety of scenarios, where $v=0.014$ represents a relatively low recycling price situation, and $v=0.02$ represents a relatively high recycling price situation; $\Delta=0.05$ represents a relatively low cost savings situation and $\Delta=0.055$ represents a relatively high cost savings situation. For parameter $c_{1}$, we set three different values to represent low, medium, and high levels, respectively. As shown in Table 6.

According to Table 6, the recycling prices, cost savings and emergency procurement costs plays an important role on the government's optimal subsidy level. Consistent with the results of Theorem 5.1, the optimal government subsidy level is divided into three situations, namely $k<m<s, m<k<s$, and $m<s<k$. 
TABLE 6. The optimal government subsidies under different parameters.

\begin{tabular}{|c|c|c|c|c|c|c|c|}
\hline \multicolumn{4}{|c|}{ Parameters } & \multicolumn{3}{|c|}{ The amount of subsidy } & \multirow[t]{2}{*}{ Size relationship } \\
\hline$v$ & $\Delta$ & $c_{1}$ & $\theta$ & $m$ & $k$ & $s$ & \\
\hline \multirow[t]{9}{*}{0.014} & 0.05 & 0.015 & 0.9 & 0.045 & 0.014 & 0.0757 & $k<m<s$ \\
\hline & & 0.03 & 0.9 & 0.028 & 0.014 & 0.0474 & \\
\hline & & 0.035 & 0.9 & 0.0234 & 0.014 & 0.0397 & \\
\hline & 0.055 & 0.015 & 0.8 & 0.044 & 0.014 & 0.2221 & \\
\hline & & 0.03 & 0.8 & 0.027 & 0.014 & 0.1372 & \\
\hline & & 0.035 & 0.8 & 0.0224 & 0.014 & 0.1139 & \\
\hline & & 0.015 & 0.9 & 0.05 & 0.014 & 0.0857 & \\
\hline & & 0.03 & 0.9 & 0.033 & 0.014 & 0.0574 & \\
\hline & & 0.035 & 0.9 & 0.0284 & 0.014 & 0.0496 & \\
\hline \multirow[t]{8}{*}{0.02} & 0.05 & 0.03 & 0.8 & 0.0107 & 0.02 & 0.0456 & $m<k<s$ \\
\hline & & 0.03 & 0.9 & 0.0167 & 0.02 & 0.0285 & \\
\hline & & 0.035 & 0.8 & 0.0052 & 0.02 & 0.0178 & $m<s<k$ \\
\hline & & 0.035 & 0.9 & 0.0112 & 0.02 & 0.0193 & \\
\hline & 0.055 & 0.03 & 0.8 & 0.0157 & 0.02 & 0.0806 & $m<k<s$ \\
\hline & & 0.03 & 0.9 & 0.0217 & 0.02 & 0.0385 & $k<m<s$ \\
\hline & & 0.035 & 0.8 & 0.0101 & 0.02 & 0.0528 & $m<k<s$ \\
\hline & & 0.035 & 0.9 & 0.0162 & 0.02 & 0.0293 & \\
\hline
\end{tabular}

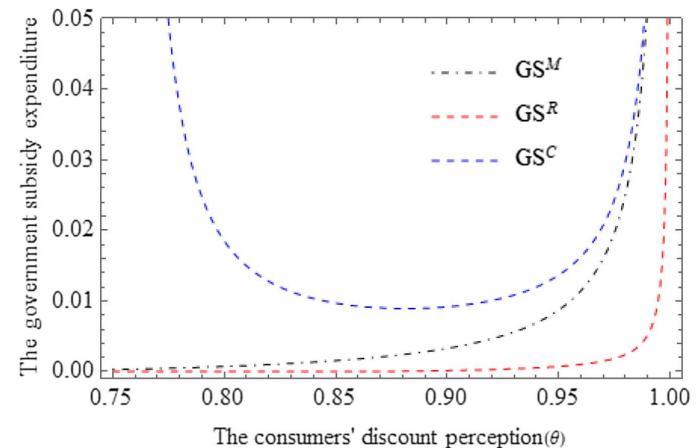

(a)

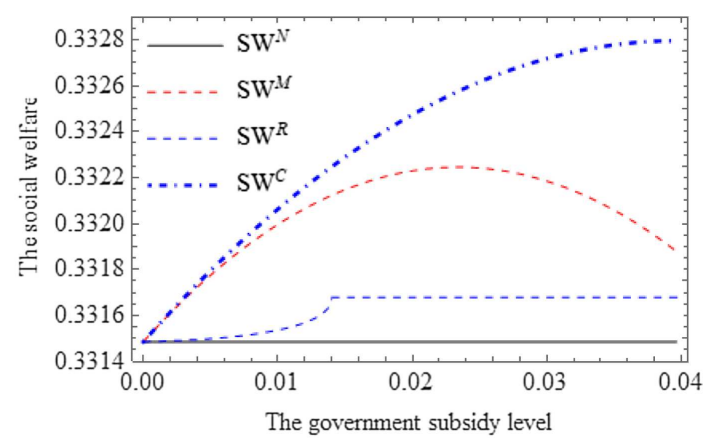

(b)

Figure 4. The total government expenditure and social welfare in Scenarios $N, M, R$, and $C$. (a) The total government expenditure. (b) The social welfare.

\subsubsection{The total government expenditure and social welfare under different scenarios}

As shown in Figure 4, the government subsidy have improved social welfare to a certain extent, but higher subsidies do not always bring higher social welfare. Specifically, in scenario $M$, the social welfare shows a trend of firstly rises and then declines. When the government's optimal subsidy reaches a certain level, it will bring huge financial pressure to the government and offset the positive benefits brought by the manufacturer's production of remanufactured products; In scenario $C$, the government expenditure and social welfare are always higher; However, in scenario $R$, although the social welfare is always the lowest compared with other subsidy scenarios (Scenarios $M$, and $C$ ), but scenario $R$ collects more EOL products with lower government expenditures under certain conditions. 


\subsection{Extension}

In the previous analysis, we assume there is no consumer's risk aversion. However, consumers may have risk aversion, which is also consistent with existing literature such as Deng [8]. Therefore, we extend the model to include consumer's risk aversion and discuss how the degree of consumer's risk aversion affects the optimal decisions of manufacturer and recycler. Beside, we use the superscript $N N, M M, R R$ and $C C$ to represent the four possible subsidy plans (corresponding to Models $N N, M M, R R$ and $C C$ ).

\subsubsection{Consumers' purchase decisions}

Based on the Section 3, we consider consumer's risk aversion in this section, we can derive the linear inverse demand functions in Models $N N, M M, R R$ and $C C$. Specifically, we assume the consumer's risk aversion degree is $r$, and follow uniform distribution between 0 and 1 . Here, a consumer's willingness to pay for the remanufactured product is adjusted from $\theta e$ to $\theta e-r$, and the willingness to pay for the new product is adjusted from $e$ to $e-h r$, where $h(h<1)$ is the ratio of consumer's risk aversion to the two types of products. Thus, for a consumer, the utility obtained by purchasing a new product and a remanufactured product is $U_{n n}^{N N}=e-h r-p_{n n}, U_{r r}^{N N}=\theta e-r-p_{r r}$ respectively. When the consumer's risk aversion is $r_{0}$, consumers will neither purchasing a new product nor a remanufactured product, where $r_{0}=\left[p_{n n}-p_{r r}-e(1-\theta)\right] /(1-h)$. When the consumer's risk aversion is $r_{0}<r<\left(e-p_{n n}\right) / h$, the consumers tend to purchase a new product, while when $0<r<r_{0}$, the consumers tend to purchase a remanufactured product. Hence, we can derive the linear inverse demand functions as follows: $P_{n n}^{N N}=e-h\left(Q_{n n}+Q_{r r}\right), P_{r r}^{N N}=e \theta-h Q_{n n}-Q_{r r}$. Note, the linear inverse demand functions for models NN, MM and RR are the same. Similarlily, in model CC, if the government subsidizes consumers who purchase a remanufactured product ( $s$ per unit), then the linear inverse demand functions as follows: $P_{n n}^{C C}=e-h\left(Q_{n n}+Q_{r r}\right), P_{r r}^{C C}=e \theta-h Q_{n n}-Q_{r r}+s$.

\subsubsection{The model results}

Substituting $P_{n n}^{N N}$ and $P_{r r}^{N N}$ into ((4.1), (4.2)), equations ((4.3), (4.4)) and equations ((4.5), (4.6)), respectively. Similarly, substituting $P_{n n}^{C C}$ and $P_{r r}^{C C}$ into (4.7) and (4.8), respectively. We can get the manufacturer's and recycler's profit functions under different subsidy schemes. Solving the four possible subsidy models can get the equilibrium solution of the supply chain members, which are summarized in Table 7 in the Appendix A.

It can be seen from Table 7 that consumers' risk aversion has no influence on the sales price of new products. For the price of remanufactured products, the relationship is as follows: $p_{r r}(M M)<p_{r r}(N N)=p_{r r}(R R)<$ $p_{r r}(C C)$, which is consistent with our previous research (Thm. 5.3). The scenarios $M M$ and $C C$ increased the sales of remanufactured products, while scenario $R R$ has no effect on the sales of remanufactured products. Moreover, when the government subsidy $k$ is trending to $v$, the scenario $R R$ may be the government's best choice if the government is more concerns about the recycling of EOL products.

\section{Conclusions}

In this paper, CLSC with the guidance of government is considered by using game theory, in which the manufacturer can produce new products or products manufactured products through waste products recovered by an independent recycler. The government needs to decide whom the subsidies should be provided to maximize social welfare. We focus on four possible models, i.e., scenario $N$, scenario $M$, scenario $R$, and scenario $C$, and analyze the optimal recycling decision of recyclers and the optimal production decision of manufacturers under different government subsidy policies. First, the demand function comes from the utility function. After obtaining the optimal response from the recycler, we discuss the optimal subsidy level of the government under different scenarios, which provided help for the government and enterprises to make decisions. Moreover, we extend our main model and confirm the robustness of our findings.

The main conclusions are as the follows: First, we obtain the government's optimal subsidy decisions with different subsidy plans and find that consumer preferences and recycling prices have different effects on government subsidy levels. Second, higher government subsidy tends to push up the price of the remanufactured 


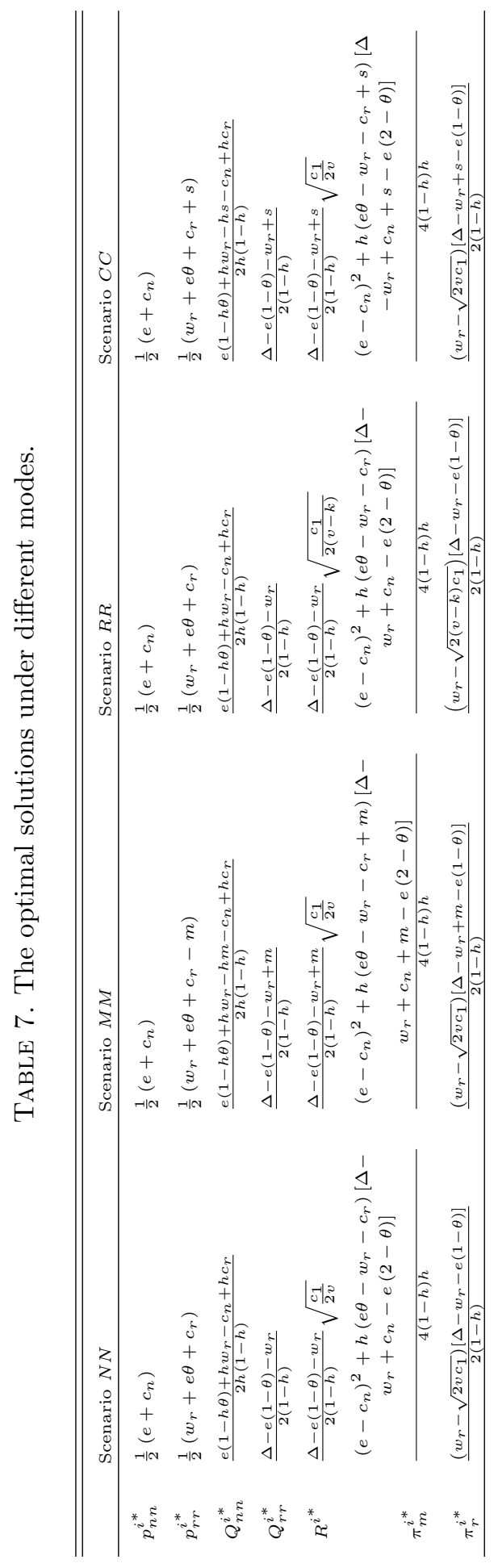


product, but the price of the new product remains unchanged. Moreover, in scenarios $N, M$, and $R$, consumers' discount perception always stimulates manufacturers to sell remanufactured products, which has a negative impact on the sales of new products. In scenario $C$, the sales quantity of the remanufactured product decreased first and then increased, while the sales quantity of the new product is opposite. Third, our research results show that compared with other subsidy scenarios, the scenario $C$ is the optimal choice for the government because it can always bring higher corporate profits and social welfare. However, the scenario $C$ will increase government expenditures and bring fiscal pressure to the government. This is similar to the results of Nielsen et al. [39], but they focus on green technologies and do not consider risk factors. For scenario $M$, government subsidies reduce the cost of remanufactured products, similar to the results of Mitra and Webster [35], both increase the sales of remanufactured products, but the effect is inferior to the scenario $C$. For scenario $R$, the government subsidies for recyclers mobilize the enthusiasm of recyclers to collect EOL products and thus improve their own profits, but the profits of manufacturers will remain unchanged. Therefore, the scenario $R$ may be resisted by manufacturers. Different from the research results of Wang et al. [49], the government subsidy should not be set too high. Fourth, our research results show that, compared with other subsidy plans, the consumer subsidy plan is the optimal choice for the government, and it always bring higher enterprise profits and social welfare. Furthermore, we also gave some policy recommendations, if the government wants to increase the output of remanufactured products or care about social welfare, the government can implement scenario $C$, but the government expenditure will increase substantially. If government funds are limited, the scenario $M$ can be considered, it should be noted that the subsidy scenario may cause social welfare losses due to higher subsidies, so setting a reasonable subsidy level is particularly important. If the purpose of the government is to effectively collect EOL products, then scenario $R$ can bring excellent results, but social welfare is significantly lower than the other two subsidy scenarios (Scenarios $M$, and $C$ ).

In addition, the following managerial insights can be drawn:

(1) Faced with different groups, the government should comprehensively consider the impact of each group's behaviour on decision-making and implement different subsidy policies to improve the operation efficiency of enterprises and social welfare according to the needs of economic and social progress.

(2) In terms of profit maximization, government subsidies will always increase profits for enterprises, but government subsidies may not necessarily increase the profits of manufacturers and recyclers at the same time, such as scenario $R$. Therefore, the government should choose the appropriate subsidy plan.

(3) As far as the government is concerned, the government must first define its goals, which is to care about social welfare, the environment, or other things; Second, consider the fiscal pressures on governments; Finally, the government should also promote environmental protection through various means (TV, radio, etc.) to enhance consumers' awareness of environmental protection.

Our research still has some limitations and can be extended in multiple directions in future work. (1) We studies the CLSC formed by a single manufacturer and recycler, and did not consider the participation of transporters, such as the impact of government subsidies on transporters. Undoubtedly, considering transporters can make our model more interesting and reasonable, which is worthwhile of independent research in the future. (2) There may be one-to-many, many-to-one, or many-to-many situations between the manufacturer and the recycler. How to integrate multiple different recyclers into the model will be our next research work. (3) We can study the competition between manufacturers and recyclers, and the difference in the quality of recycled EOL product.

\section{Appendix A.}

Proofs for Proposition 4.1. In this case, the decision of the CLSC can be regarded as a two-stage Stackelberg game problem, in which the manufacturer and the recycler are the leader and follower respectively. According to the idea of backward induction, the expected profit of the recycler is a concave function of the recycling 
quantity $R$, and there is a unique optimal $R$ to maximize the profit of the recycler. Where, $R$ should satisfy:

$$
\begin{aligned}
\frac{\mathrm{d} \pi_{r}^{N}}{\mathrm{dR}} & =-v-\left(\int_{0}^{\frac{Q_{r}}{R}}-\lambda f[\lambda] \mathrm{d} \lambda\right) c_{1} \\
\frac{\mathrm{d}^{2} \pi_{r}^{N}}{\mathrm{~d} R^{2}} & =\frac{-F\left[\frac{Q_{r}}{R}\right] c_{1} Q_{r}^{2}}{R^{3}}<0 .
\end{aligned}
$$

Therefore, according to the hypothesis and when $\frac{d \pi_{r}^{N}}{d R}=0$, the optimal recycling amount $R$ can be obtained to maximize the profits of the recycler

$$
R^{*}=\frac{w_{r}-\theta c_{n}+c_{r}}{2 \theta(-1+\theta)} \sqrt{\frac{c_{1}}{2 v}}
$$

The Hessian matrix of the manufacturer's profit function regarding the number of sales of the new product and the remanufactured product is

$$
H_{m}^{N}\left(Q_{n}^{N}, Q_{r}^{N}\right)=\left[\begin{array}{ll}
\frac{\partial^{2} \pi_{m}^{N}}{\partial \mathrm{Q}_{n}^{N 2}} & \frac{\partial^{2} \pi_{m}^{N}}{\partial \mathrm{Q}_{n}^{N} \partial \mathrm{Q}_{r}^{N}} \\
\frac{\partial^{2} \pi_{m}^{N}}{\partial \mathrm{Q}_{r}^{N} \partial \mathrm{Q}_{n}^{N}} & \frac{\partial^{2} \pi_{m}^{N}}{\partial \mathrm{Q}_{r}^{N}}
\end{array}\right]=\left[\begin{array}{ll}
-2 & -2 \theta \\
-2 \theta & -2 \theta
\end{array}\right] .
$$

According to the hypothesis $0<\theta<1$, it is known $\partial^{2} \pi_{m} / \partial Q_{n}^{2}=-2<0$ and $\left|H_{m}^{N}\right|=4 \theta(1-\theta)>0$. Therefore, the manufacturer's profit function is a joint concave function about the sales volume of new products and remanufactured products, so there is an optimal solution. Set the first order partial derivative $\partial \pi_{m}^{N} / \partial Q_{n}^{N}=0, \partial \pi_{m}^{N} / \partial Q_{r}^{N}=0$. The optimal response of retailers can be obtained as follows $Q_{r}^{N}=$ $\frac{w_{r}-\theta c_{n}+c_{r}}{2(-1+\theta) \theta}, Q_{n}^{N}=\frac{1+w_{r}-\theta-c_{n}+c_{r}}{2-2 \theta}$. By substituting it into the inverse demand function, the sales price of the new product and the remanufactured product can be obtained as $p_{r}^{N}=\frac{w_{r}+\theta+c_{r}}{2}, p_{n}^{N}=\frac{1+c_{n}}{2}$.

The proof of Propositions 4.2-4.4 are similar to Proposition 4.1.

Proof of Proposition 4.4. According to assumption, we can get the social welfare function. Therefore, the social welfare function of scenario $M$ can be expressed as

$$
\begin{aligned}
\mathrm{SW}^{M}= & \pi_{m}^{M}+\pi_{r}^{M}+\mathrm{CS}^{M}-\mathrm{GS}^{M} \\
= & \frac{1}{8(-1+\theta) \theta}\left[\left(m-w_{r}\right)^{2}+3(-1+\theta) \theta-3 \theta c_{n}^{2}+4 c_{2}\left(m-w_{r}+\theta c_{n}-c_{r}\right)\right. \\
& \left.+\left(2 m-2 w_{r}-3 c_{r}\right) c_{r}+2 \theta c_{n}\left(3-m+w_{r}-3 \theta+3 c_{r}\right)\right] .
\end{aligned}
$$

We first check the condition of optimal solution existing. By taking the second-order derivative of $\mathrm{SW}^{M}$ with respect to resulting in $\frac{\mathrm{d}^{2} \mathrm{SW}^{M}}{\mathrm{~d} m^{2}}=\frac{1}{4(-1+\theta) \theta}<0$, which means that the model in $M$ scenario exists unique optimal solution: $m^{*}=w-\frac{2 c_{1}}{\sqrt{\frac{c_{1}}{2 v}}}+\theta c_{n}-c_{r}$.

Likewise, we can get the social welfare function of the $M$ scenario:

$$
\begin{aligned}
\mathrm{SW}^{R}= & \pi_{m}^{R}+\pi_{r}^{R}+\mathrm{CS}^{R}-\mathrm{GS}^{R} \\
= & \frac{1}{8(-1+\theta) \theta}\left[w_{r}^{2}-\theta+2(-1+\theta) \theta+\theta^{2}-3 \theta c_{n}^{2}-2 w_{r} c_{r}-3 c_{r}^{2}+4 \theta c_{n}\left(1-\theta+c_{r}\right)+2 \theta c_{n}\left(1+w_{r}-\theta c_{r}\right)\right. \\
& \left.-4 k\left(w_{r}-\theta c_{n}+c_{r}\right)-\frac{4 c_{1}\left(w_{r}-\theta c_{n}+c_{r}\right)}{\sqrt{\frac{c_{1}}{2 v-2 k}}}-\frac{4 c_{2}\left(-1+\sqrt{\frac{c_{1}}{2 v-2 k}}\left(w_{r}-\theta c_{n}+c_{r}\right)\right)}{\sqrt{\frac{c_{1}}{2 v-2 k}}}\right] .
\end{aligned}
$$


Taking first-order derivatives of $\mathrm{SW}^{R}$ with respect to $k$ yields the following results:

$$
\frac{\partial \mathrm{SW}^{R}}{\partial k}=\frac{\left(-1+\sqrt{\frac{c_{1}}{2 v-2 k}}\right)\left(w_{r}-\theta c_{n}+c_{r}\right)}{2(-1+\theta) \theta}
$$

while $g^{\prime}(k)=\frac{\left(-1+\sqrt{\frac{c_{1}}{2 v-2 k}}\right)\left(w_{r}-\theta c_{n}+c_{r}\right)}{2(-1+\theta) \theta}$, then $g^{\prime}(0)=\frac{\left(-1+\sqrt{\frac{c_{1}}{2 v}}\right)\left(w_{r}-\theta c_{n}+c_{r}\right)}{2(-1+\theta) \theta}$. While $v \leq \frac{1}{2} c_{1}$, get $g^{\prime}(0) \geq 0$. While $g^{\prime}(v)=\frac{\left(-1+\sqrt{\frac{c_{1}}{2 v-2 k}}\right)\left(w_{r}-\theta c_{n}+c_{r}\right)}{2(-1+\theta) \theta}$. When $v$ is infinitely close to $k$, get $g^{\prime}(v)>0$. So $g(k)$ is an increasing function, and the model in $R$ scenario exists unique optimal solution: $k=v$. Similarly, while $g^{\prime}(0)<0, g^{\prime}(v)<0$, then $k=0, g(k)$ is a descending function. While $g^{\prime}(0)\left\langle 0, g^{\prime}(v)\right\rangle 0$, then $g(k)$ decreased and then increased.

Substitute $k=v$ and $k=0$ into the $\mathrm{SW}^{K}$ function, and subtract them to get $\frac{1}{2} v\left(-1+\sqrt{\frac{2 c_{1}}{v}}\right)>0$. So the optimal value of $k$ is $k^{*}=v$.

The proofs of government subsidies in $C$ scenario is similar to that in $M$ scenario. By taking the second-order derivative of $\mathrm{SW}^{C}$ with respect to resulting in $\frac{\mathrm{d}^{2} \mathrm{SW}}{\mathrm{d} s^{2}}=\frac{3-4 \theta}{4 \theta-4 \theta^{2}}$. Therefore, we give the existence condition of the optimal solution $\frac{3}{4}<\theta<1$. The expressions of social welfare in $C$ scenario can be given by

$$
\begin{aligned}
\mathrm{SW}^{C}= & \pi_{m}^{C}+\pi_{r}^{C}+\mathrm{CS}^{C}-\mathrm{GS}^{C} \\
= & \frac{1}{8(-1+\theta) \theta}\left[-3 s^{2}+2 s w_{r}+w_{r}^{2}-3 \theta+4 s^{2} \theta-4 s w_{r} \theta+3 \theta^{2}-3 \theta c_{n}^{2}\right. \\
& +4 \sqrt{2 c_{1} v}\left(s-w_{r}+\theta c_{n}-c_{r}\right)-2\left(w_{r}+s(-3+2 \theta)\right) c_{r}-3 c_{r}^{2} \\
& \left.+2 \theta c_{n}\left(3+w_{r}-3 \theta+s(-3+2 \theta)+3 c_{r}\right)\right] .
\end{aligned}
$$

The government subsidies to Recycler in $C$ scenario exists unique optimal solution:

$$
s^{*}=\frac{-2 c_{1}+\sqrt{\frac{c_{1}}{2 v}}\left(w_{r}(-1+2 \theta)+(3-2 \theta) \theta c_{n}+(-3+2 \theta) c_{r}\right)}{(-3+4 \theta) \sqrt{\frac{c_{1}}{2 v}}} .
$$

The expressions of social welfare in $N$ scenario can be given by.

$$
\begin{aligned}
\mathrm{SW}^{N} & =\pi_{m}^{N}+\pi_{r}^{N}+\mathrm{CS}^{N}-\mathrm{GS}^{N} \\
& =\frac{w_{r}^{2}-3 \theta+3 \theta^{2}-3 \theta c_{n}^{2}-2 w_{r} c_{r}-3 c_{r}^{2}-4 \sqrt{2 c_{1} v}\left(w_{r}-\theta c_{n}+c_{r}\right)+2 \theta c_{n}\left(3+w_{r}-3 \theta+3 c_{r}\right)}{8(-1+\theta) \theta} .
\end{aligned}
$$

We first take the optimal responsive solutions of each model into (4.1)-(4.8) to obtain the following equations.

$$
\begin{array}{ll}
\pi_{m}^{N} & -\frac{w_{r}^{2}+\theta-\theta^{2}+\theta c_{n}^{2}+2 w_{r} c_{r}+c_{r}^{2}-2 \theta c_{n}\left(1+w_{r}-\theta+c_{r}\right)}{4(-1+\theta) \theta} \\
\pi_{m}^{M} & -\frac{\left(m-w_{r}\right)^{2}+\theta-\theta^{2}+\theta c_{n}\left(2\left(-1+m-w_{r}+\theta\right)+c_{n}\right)-2\left(m-w_{r}+\theta c_{n}\right) c_{r}+c_{r}^{2}}{4(-1+\theta) \theta} \\
\pi_{m}^{R} & -\frac{w_{r}^{2}+\theta-\theta^{2}+\theta c_{n}^{2}+2 w_{r} c_{r}+c_{r}^{2}-2 \theta c_{n}\left(1+w_{r}-\theta+c_{r}\right)}{4(-1+\theta) \theta} \\
\pi_{m}^{C} & -\frac{\left(s-w_{r}\right)^{2}+\theta-\theta^{2}+\theta c_{n}\left(2\left(-1+s-w_{r}+\theta\right)+c_{n}\right)-2\left(s-w+\theta c_{n}\right) c_{r}+c_{r}^{2}}{4(-1+\theta) \theta} \\
\pi_{r}^{N} & -\frac{\left(c_{1}-w_{r} \sqrt{\frac{c_{1}}{2 v}}+c_{2}\left(-1+\sqrt{\frac{c_{1}}{2 v}}\right)\right)\left(w_{r}-\theta c_{n}+c_{r}\right)}{2(-1+\theta) \theta \sqrt{\frac{c_{1}}{2 v}}} \\
\pi_{r}^{M} & \frac{\left(c_{1}-w_{r} \sqrt{\frac{c_{1}}{2 v}}\right)\left(m-w_{r}+\theta c_{n}-c_{r}\right)}{2(-1+\theta) \theta \sqrt{\frac{c_{1}}{2 v}}}
\end{array}
$$




$$
\begin{aligned}
& \pi_{r}^{R} \quad \frac{\left(w_{r} \sqrt{\frac{c_{1}}{2 v-2 k}}-\sqrt{2} c_{1}\right)\left(w_{r}-\theta c_{n}+c_{r}\right)}{2(-1+\theta) \theta \sqrt{\frac{c_{1}}{2 v-2 k}}} \\
& \pi_{r}^{C} \quad \frac{\left(c_{1}-w_{r} \sqrt{\frac{c_{1}}{2 v}}+c_{2}\left(-1+\sqrt{\frac{c_{1}}{2 v}}\right)\right)\left(s-w_{r}+\theta c_{n}-c_{r}\right)}{2(-1+\theta) \theta \sqrt{\frac{c_{1}}{2 v}}} \\
& \mathrm{CS}^{N} \quad-\frac{w_{r}^{2}+\theta-\theta^{2}+\theta c_{n}^{2}+2 w_{r} c_{r}+c_{r}^{2}-2 \theta c_{n}\left(1+w_{r}-\theta+c_{r}\right)}{8(-1+\theta) \theta} \\
& \mathrm{CS}^{M}-\frac{\left(m-w_{r}\right)^{2}+\theta-\theta^{2}+\theta c_{n}\left(2\left(-1+m-w_{r}+\theta\right)+c_{n}\right)-2\left(m-w_{r}+\theta c_{n}\right) c_{r}+c_{r}^{2}}{8(-1+\theta) \theta} \\
& \mathrm{CS}^{R} \quad-\frac{w_{r}^{2}+\theta-\theta^{2}+\theta c_{n}^{2}+2 w_{r} c_{r}+c_{r}^{2}-2 \theta c_{n}\left(1+w_{r}-\theta+c_{r}\right)}{8(-1+\theta) \theta} \\
& \mathrm{CS}^{C}-\frac{w_{r}^{2}+s^{2}(5-4 \theta)+\theta-\theta^{2}+2 s w_{r}(-3+2 \theta)+\theta c_{n}^{2}-2 \theta c_{n}\left(1-3 s+w_{r}-\theta+2 s \theta+c_{r}\right)+c_{r}\left(-6 s+2 w_{r}+4 s \theta+c_{r}\right)}{8(-1+\theta) \theta} \\
& \mathrm{GS}^{N} \quad- \\
& \mathrm{GS}^{M} \frac{m\left(m-w_{r}+\theta c_{n}-c_{r}\right)}{2 \theta-2 \theta^{2}} \\
& \mathrm{GS}^{R} \quad \frac{k\left(w_{r}-\theta c_{n}+c_{r}\right)}{2 \theta^{2}-2 \theta} \\
& \mathrm{GS}^{C} \quad \frac{s\left(s-w_{r}+\theta c_{n}-c_{r}\right)}{2 \theta-2 \theta^{2}} .
\end{aligned}
$$

Proof of Theorem 5.1. According to conditional $w_{r}>c_{1}>v, c_{n}>w_{r}+c_{r}, \theta-1<w_{r}-\theta c_{n}+c_{r}<0$. We can get $\theta c_{n}-c_{r}>\sqrt{2 v c_{1}}, w_{r}>\sqrt{2 v c_{1}} \cdot m-s=\frac{2(-1+\theta)\left(w-4 \sqrt{2 v c_{1}}+3 \theta c_{n}-3 c_{r}\right)}{-3+4 \theta}<0, m$ is always less than $s$. Therefore, government subsidies have three forms of size. $k<m<s, m<k<s$ and $m<s<k$. Then, pairwise comparison can determine the boundary of government subsidies in three cases.

Proof of Theorem 5.2. It can be easily proved by calculating $p_{n}(N)=p_{n}(R)=p_{n}(M)=p_{n}(C)$.

Proof of Theorem 5.3. It can be easily proved by calculating $p_{r}(M)-p_{r}(N)<0, p_{r}(C)-p_{r}(N)>0$. $p_{r}(M)<$ $p_{r}(N)=p_{r}(R)<p_{r}(C)$.

Proof of Theorem 5.4. It can be easily proved by calculating $Q_{n}(M)-Q_{n}(N)<0, Q_{n}(C)-Q_{n}(N)<0$. $Q_{n}(M)-Q_{n}(S)=\frac{w_{r}-4 \sqrt{2} v \sqrt{\frac{c_{1}}{v}}+3 \theta c_{n}-3 c_{r}}{-3+4 \theta}$. Therefore, when $c_{1}<\frac{\left(w_{r}+3 \theta c_{n}-3 c_{r}\right)^{2}}{32 v}, Q_{n}(M)>Q_{n}(S)$. $Q_{n}(S)<$ $Q_{n}(M)<Q_{n}(R)=Q_{n}(N)$; When $c_{1}>\frac{\left(w_{r}+3 \theta c_{n}-3 c_{r}\right)^{2}}{32 v}, Q_{n}(M)<Q_{n}(C) . Q_{n}(M)<Q_{n}(C)<Q_{n}(R)=$ $Q_{n}(N)$.

Proof of Theorem 5.5. It can be easily proved by calculating $Q_{r}(M)-Q_{r}(N)>0, Q_{r}(C)-Q_{r}(N)>0$. $Q_{r}(M)-Q_{r}(C)=\frac{w_{r}-4 \sqrt{2} v \sqrt{\frac{c_{1}}{v}}+3 \theta c_{n}-3 c_{r}}{3 \theta-4 \theta^{2}}$. Therefore, when $c_{1}>\frac{\left(w_{r}+3 \theta c_{n}-3 c_{r}\right)^{2}}{32 v}, Q_{r}(M)>Q_{r}(C) . Q_{r}(N)=$ $Q_{r}(R)<Q_{r}(C)<Q_{r}(M)$. When $c_{1}<\frac{\left(w_{r}+3 \theta c_{n}-3 c_{r}\right)^{2}}{32 v}, Q_{r}(M)<Q_{r}(C)$. When $\min \left\{\frac{\left(w_{r}+3 \theta c_{n}-3 c_{r}\right)^{2}}{32 v}, w_{r}\right\}$, $Q_{r}(N)=Q_{r}(R)<Q_{r}(M)<Q_{r}(C)$.

Proof of Theorem 5.6. Similarly, $R(M)-R(N)>0, R(C)-R(N)>0 . R(M)-R(C)=$ $\frac{\sqrt{\frac{c_{1}}{v}}\left(-w_{r}+4 \sqrt{2} v \sqrt{\frac{c_{1}}{v}}-3 \theta c_{n}+3 c_{r}\right)}{\sqrt{2} \theta(-3+4 \theta)}$.

Therefore, When $c_{1}<\frac{\left(w_{r}+3 \theta c_{n}-3 c_{r}\right)^{2}}{32 v}, R(C)<R(M)$. When $\min \left\{\frac{\left(w_{r}+3 \theta c_{n}-3 c_{r}\right)^{2}}{32 v}, w_{r}\right\}, R(N)<R(C)<$ $R(M)<R(R)$. 
Proof of Section 6.4. The utility obtained by purchasing a new product and a remanufactured product is: $U_{n n}=e-h r-p_{n n} ; U_{r r}=\theta e-r-p_{r r}$. When $U_{n n}=U_{r r}$, we can get $r_{0}=\left[p_{n n}-p_{r r}-e(1-\theta)\right] /(1-h)$. $U_{n n}>0$, we can get $r<\left(e-p_{n n}\right) / h$. Hence, when the consumer's risk aversion is $r_{0}<r<\left(e-p_{n n}\right) / h$, the consumers tend to purchase a new product, while when $0<r<r_{0}$, the consumers tend to purchase a remanufactured product. The demand functions for new products and remanufactured products can be expressed as:

$$
\left\{\begin{array}{l}
Q_{n n}=\int_{\frac{e-p_{n n}}{h}}^{\frac{p_{n n}-p_{r r}-e(1-\theta)}{1-h}} 1 \mathrm{~d} r=\frac{e(1-h \theta)-p_{n n}+h p_{r r}}{h(1-h)} \\
Q_{r r}=\int_{0}^{\frac{p_{n n}-p_{r r}-e(1-\theta)}{1-h}} 1 \mathrm{~d} r=\frac{p_{n n}-p_{r r}-e(1-\theta)}{1-h}
\end{array} .\right.
$$

Hence, we can derive the linear inverse demand functions as follows:

$$
\left\{\begin{array}{l}
p_{n n}=e-h\left(Q_{n n}+Q_{r r}\right) \\
p_{r r}=e \theta-h Q_{n n}-Q_{r r}
\end{array} .\right.
$$

The proof in this section is similar to that in Section 4 and is omitted.

Acknowledgements. The authors sincerely thank the anonymous editors and reviewers for their valuable suggestions and comments. This research was supported by National Natural Science Foundation of China [No.71974123] and Innovation Program of Shanghai Municipal Education Commission [No. 2017-01-07-00-10-E00016].

\section{REFERENCES}

[1] J.D. Abbey, M.G. Meloy, V.D.R. Guide and S. Atalay, Remanufactured products in closed-loop supply chains for consumer goods. Prod. Oper. Manag. 24 (2015) 488-503.

[2] A. Atasu, M. Sarvary and L.N. Van Wassenhove, Remanufacturing as a marketing strategy. Manag. Sci. 54 (2008) $1731-1746$.

[3] R. Banker and S.C. Hansen, The Adequacy of Full Cost Based Pricing Heuristics. UT Dallas and UCLA, Mimeo (2000).

[4] J. Bian, G. Zhang and G. Zhou, Manufacturer vs. consumer subsidy with green technology investment and environmental concern. Eur. J. Oper. Res. 287 (2020) 832-843.

[5] T.-M. Choi, C. Ma, B. Shen and Q. Sun, Optimal pricing in mass customization supply chains with risk-averse agents and retail competition. Omega $\mathbf{8 8}$ (2019) 150-161.

[6] M.C. Cohen, R. Lobel and G. Perakis, The impact of demand uncertainty on consumer subsidies for green technology adoption. Manag. Sci. 62 (2016) 1235-1258.

[7] L.G. Debo, L.B. Toktay and L.N. Van Wassenhove, Market segmentation and product technology selection for remanufacturable products. Manag. Sci. 51 (2005) 1193-1205.

[8] W. Deng, Sustainable development: impacts of consumers' risk aversionon remanufacturing model selection and environmental performance. Sustain. Dev. 28 (2020) 1564-1574.

[9] S. Du, J. Zhu, H. Jiao and W. Ye, Game-theoretical analysis for supply chain with consumer preference to low carbon. Int. J. Prod. Res. 53 (2015) 3753-3768.

[10] Electronic-Waste-Facts, https://www.itu.int/en/ITU-D/Climate-Change/Pages/Global-E-waste-Monitor-2017.aspx (2017).

[11] Z.-P. Fan, Y. Cao, C.-Y. Huang and Y. Li, Pricing strategies of domestic and imported electric vehicle manufacturers and the design of government subsidy and tariff policies. Transp. Res. E-LOG. 143 (2020) 102093.

[12] G. Ferrer and J.M. Swaminathan, Managing new and differentiated remanufactured products. Eur. J. Oper. Res. 203 (2010) 370-379.

[13] L. Feng, K. Govindan and C. Li, Strategic planning: design and coordination for dual-recycling channel reverse supply chain considering consumer behavior. Eur. J. Oper. Res. 260 (2017) 601-612.

[14] J. Fu, X. Chen and Q. Hu, Subsidizing strategies in a sustainable supply chain. J. Oper. Res. Soc. 69 (2017) $283-295$.

[15] S.S. Gan, I.N. Pujawan Suparno and B. Widodo, Pricing decision for new and remanufactured products in a closed-loop supply chain with a separate sales-channel. Int. J. Prod. Econ. 190 (2016) 120-132.

[16] V. Gupta and D. Ivanov, Dual sourcing under supply disruption with risk-averse suppliers in the sharing economy. Int. J. Prod. Res. 58 (2020) 291-307.

[17] X. Han, Q. Yang, J. Shang and X. Pu, Optimal strategies for trade-old-for-remanufactured programs: receptivity, durability, and subsidy. Int. J. Prod. Econ. 193 (2017) 602-616.

[18] S.M. Hatefi and F. Jolai, Robust and reliable forward-reverse logistics network design under demand uncertainty and facility disruptions. Appl. Math. Model. 9 (2014) 2630-2647.

[19] Y.J. He, Acquisition pricing and remanufacturing decisions in a closed-loop supply chain. Int. J. Prod. Econ. 163 (2015) 48-60. 
[20] P. He, Y. He and H. Xu, Channel structure and pricing in a dual-channel closed-loop supply chain with government subsidy. Int. J. Prod. Econ. 213 (2019) 108-123.

[21] J. Heydari and M. Ghasemi, A revenue sharing contract for reverse supply chain coordination under stochastic quality of returned products and uncertain remanufacturing capacity. J. Clean. Prod. 197 (2018) 607-615.

[22] B. Hu and Y. Feng, Optimization and coordination of supply chain with revenue sharing contracts and service requirement under supply and demand. Int. J. Prod. Econ. 183 (2017) 185-193.

[23] W. Huang, W. Zhou, J. Chen and X. Chen, The government's optimal subsidy scheme under Manufacturers' competition of price and product energy efficiency. Omega 84 (2019) 70-101.

[24] M. Jeihoonian, M.K. Zanjani and M. Gendreau, Closed-loop supply chain network design under uncertain quality status: case of durable products. Int. J. Prod. Econ. 183 (2017) 470-486.

[25] S.K. Jena and S.P. Sarmah, Price and service co-opetiton under uncertain demand and condition of used items in a remanufacturing system. Int. J. Prod. Econ. 173 (2016) 1-21.

[26] S.K. Jena, S.P. Sarmah and S.C. Sarin, Joint-advertising for collection of returned products in a closed-loop supply chain under uncertain environment. Comput. Ind. Eng. 113 (2017) 305-322.

[27] Y. Ji, S. Qu, Z. Wu and Z. Liu, A fuzzy-robust weighted approach for multicriteria bilevel games. IEEE. Trans. Ind. Inform. 16 (2020) 5369-5376.

[28] M. Khouja, S. Park and G. Cai, Channel selection and pricing in the presence of retail-captive consumers. Int. J. Prod. Econ. 125 (2010) 84-95.

[29] C. Li, L. Feng and S. Luo, Strategic introduction of an online recycling channel in the reverse supply chain with a random demand. J. Clean. Prod. 236 (2019) 117683.

[30] H. Liu, M. Lei, H. Deng, G.K. Leong and T. Huang, A dual channel, quality-based price competition model for the WEEE recycling market with government subsidy. Omega 59 (2016) 290-302.

[31] W. Ma, Z. Zhao and H. Ke, Dual-channel closed-loop supply chain with government consumption-subsidy. Eur. J. Oper. Res. 226 (2013) 221-227.

[32] L. Ma, Y. Liu and Y. Liu, Distributionally robust design for bicycle-sharing closed-loop supply chain network under risk-averse criterion. J. Clean. Prod. 246 (2019) 118967.

[33] D.M. Mcconocha and T.W. Speh, Remarketing: commercialization of remanufacturing technology. J. Bus. Ind. Mark. 6 (1991) 23-37.

[34] X. Meng, Z. Yao, J. Nie and Y. Zhao, Make or buy? It is the question: a study in the presence of carbon tax. Int. J. Prod. Econ. 195 (2018) 328-337.

[35] S. Mitra and S. Webster, Competition in remanufacturing and the effects of government subsidies. Int. J. Prod. Econ. 111 (2008) 287-298.

[36] M. Motoshita, M. Sakagami, Y. Kudoh, K. Tahara and A. Inaba, Potential impacts of information disclosure designed to motivate Japanese consumers to reduce carbon dioxide emissions on choice of shopping method for daily foods and drinks. J. Clean. Prod. 101 (2015) 205-214.

[37] A. Mutha, S. Bansal, V.D.R. Guide, Managing demand uncertainty through core acquisition in remanufacturing. Prod. Oper. Manag. 25 (2016) 1449-1464.

[38] M.A. Naeem, D.J. Dias, P.C. Chang and M.K. Tiwari, Production planning optimization for manufacturing and remanufacturing system in stochastic environment. J. Intell. Manuf. 24 (2013) 717-728.

[39] I.E. Nielsen, S. Majumder and S. Saha, Game-theoretic analysis to examine how government subsidy policies affect a closed-loop supply chain decision. Appl. Sci. 10 (2019) 145.

[40] M. Ouhimmou, N. Mustapha, M. Bouchard and N. Bricha, Design of robust distribution network under demand uncertainty: a case study in the pulp and paper. Int. J. Prod. Econ. 218 (2019) 96-105.

[41] Q. Peng, C. Wang and L. Xu, Emission abatement and procurement strategies in a low-carbon supply chain with option contracts under stochastic demand. Comput. Ind. Eng. 144 (2020) 106502.

[42] S. Prakash, G. Soni and A.P.S Rathore, Embedding risk in closed-loop supply chain network design Case of a hospital furniture manufacturer. J. Mod. I. Manag. 12 (2017) 551-574.

[43] S. Qu, Y. Zhou, Y. Zhang, M.I.M. Wahab, G. Zhang and Y. Ye, Optimal strategy for a green supply chain considering shipping policy and default risk. Comput. Ind. Eng. 131 (2019) 172-186.

[44] B.D. Rhee, Consumer heterogeneity and strategic quality decisions. Manag. Sci. 42 (1996) 157-172.

[45] R.C. Savaskan, S. Bhattacharya and L.N. Van Wassenhove, Closed-loop supply chain models with product remanufacturing. Manag. Sci. 50 (2004) 239-252.

[46] L. Shao, J. Yang and M. Zhang, Subsidy scheme or price discount scheme? Mass adoption of electric vehicles under different market structures. Eur. J. Oper. Res. 262 (2017) 1181-1195.

[47] C.M. Shuai, L.P. Ding, Y.K. Zhang, Q. Guo and J. Shuai, How consumers are willing to pay for low-carbon products? - Results from a carbon-labeling scenario experiment in china. J. Clean. Prod. 83 (2014) 366-373.

[48] H. Soleimani, M. Seyyed-Esfahani and M.A. Shirazi, A new multi-criteria scenario-based solution approach for stochistic forward/reverse supply chain network design. Ann. Oper. Res. 242 (2016) 399-421.

[49] Y. Wang, X. Chang, Z. Chen, Y. Zhong and T. Fan, Impact of subsidy policies on recycling and remanufacturing using system dynamics methodology: a case of auto parts in China. J. Clean. Prod. 74 (2014) 161-171.

[50] C. Wang, W. Wang and R. Huang, Supply chain enterprise operations and government carbon tax decisions considering carbon emissions. J. Clean. Prod. 152 (2017) 271-280. 
[51] W. Wang, Y. Zhang, Y. Li, X. Zhao and M. Chen, Closed-loop supply chains under reward-penalty mechanism: retailer collection and asymmetric information. J. Clean. Prod. 142 (2017) 3938-3955.

[52] S. Wei, D. Cheng, E. Sundin and O. Tang, Motives and barriers of the remanufacturing industry in china. J. Clean. Prod. 94 (2015) 340-351.

[53] L. Xiao, X. Wang, K.S. Chin and Y. Qin, Competitive strategy in remanufacturing and the effects of government subsidy. J. Syst. Sci. Syst. Eng. 26 (2017) 417-432.

[54] Y. Xiong, Y. Zhou, G. Li, H. Chan and Z. Xiong, Don't forget your supplier when remanufacturing. Eur. J. Oper. Res. 230 (2013) 15-25.

[55] L. Xu, C. Wang and J. Zhao, Decision and coordination in the dual-channel supply chain considering cap-and-trade regulation. J. Clean. Prod. 197 (2018) 551-561.

[56] L. Xu, C. Wang, Z. Miao and J. Chen, Governmental subsidy policies and supply chain decisions with carbon emission limit and consumer's environmental awareness. RAIRO:OR 53 (2019) 1675-1689.

[57] L. Xu, F. Xie, Q. Yuan and J. Chen, Pricing and carbon footprint in a two-echelon supply chain under cap-and-trade regulation. Int. J. Low-Carbon Tec. 14 (2019) 212-221.

[58] C. Xu, C. Wang and R. Huang, Impacts of horizontal integration on social welfare under the interaction of carbon tax and green subsidies. Int. J. Prod. Econ. 222 (2020) 107506.

[59] L. Xu, J. Shi and J.H. Chen, Pricing and collection rate for remanufacturing industry considering capacity constraint in recycling channels. Complexity (2020). DOI: 10.1155/2020/8391252.

[60] L. Xu, J. Shi and J.H. Chen, Effect of capital constraint in a dual-channel supply chain. Complexity (2020). DOI: $10.1155 / 2020 / 1585270$.

[61] J. Yu, C. Tang and Z. Shen, Improving consumer welfare and manufacturer profit via government subsidy programs: subsidizing consumers or manufacturers? Manuf. Serv. Oper. Manag. 20 (2018) 752-766.

[62] L. Zhang, J. Wang and J. You, Consumer environmental awareness and channel coordination with two substitutable products. Eur. J. Oper. Res. 241 (2015) 63-73.

[63] J. Zhao, C. Wang and L. Xu, Decision for pricing, service, and recycling of closed-loop supply chains considering different remanufacturing roles and technology authorizations. Comput. Ind. Eng. 132 (2019) 59-73.

[64] S. Zhao and Q. Zhu, Remanufacturing supply chain coordination under the stochastic remanufacturability rate and the random demand. Ann. Oper. Res. 257 (2017) 661-695.

[65] X. Zhu, M. Ren, W. Chu and R. Chiong, Remanufacturing subsidy or carbon regulation? An alternative toward sustainable production. J. Clean. Prod. 239 (2019) 117988. 